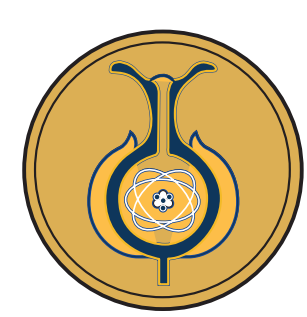

\title{
La formación universitaria de docentes de educación primaria: el caso de matemáticas
}

\author{
College education of elementary school teachers: the case of mathematics
}

A formação universitária de docentes do ensino fundamental: o caso da matemática

\author{
Marianela Alpízar-Vargas \\ marianela.alpizar.vargas@una.ac.cr \\ Escuela de Matemática \\ Universidad Nacional, \\ Heredia, Costa Rica. \\ Orcid: http://orcid.org/0000-0002-3515-1971
}

\author{
Ana Lucía Alfaro-Arce \\ ana.alfaro.arce@una.ac.cr \\ Escuela de Matemática \\ Universidad Nacional, \\ Heredia, Costa Rica.
}

Orcid: http://orcid.org/0000-0002-9859-9474

Recibido-Received: 27/jun/2018/Corregido-Corrected: 12/dic /2018.

Aceptado-Accepted: 14/mar/2019/Publicado-Published: 31/jul/2019.

\section{Resumen}

En este artículo, se hace una descripción de los programas de formación ofrecidos en universidades estatales y privadas de Costa Rica, para obtener el grado de enseñanza en I y II ciclos de la educación general básica. La investigación es cualitativa de corte descriptivo. Se efectuó una revisión documental de los planes de estudio de las diversas universidades y se entrevistaron coordinadores de carreras afines de distintas casas de estudio, así como profesores de matemáticas de estas. El análisis reveló una amplia variedad de dichos programas para formar docentes de educación primaria, sin lineamientos generales y poco control. En Costa Rica, no existen regulaciones sobre el propósito, la duración, el perfil ni los contenidos de estos programas, lo cual podría afectar la enseñanza de matemáticas en las instituciones de educación primaria, ya que llegan docentes con énfasis distintos en su formación.

Palabras claves: enseñanza de las matemáticas; formación docente; formación universitaria; educación primaria.

\begin{abstract}
This article describes the curricula offered by state and private universities in Costa Rica to obtain a teaching degree in cycles I and II of elementary education. The study is qualitative and descriptive. Curricula from different universities were reviewed, and coordinators of related programs and math professors from those universities were interviewed. The analysis revealed a wide variety of study programs to train elementary school teachers with no general guidelines and little control. Therefore, there are no regulations in Costa Rica for these programs' purposes, duration, content or teacher profile, which could affect math education in elementary schools since teachers come from programs with different emphasis.
\end{abstract}

Keywords: teaching math; teacher training; college education; elementary school. 


\section{Resumo}

Neste artigo, é dada uma descrição dos planos de estudo oferecidos nas universidades estaduais e particulares da Costa Rica para obter o grau de instrução nos ciclos I e II da educação básica geral. 0 estudo é qualitativo-descritivo. Foi realizada uma revisão documental dos currículos das diferentes universidades e foram entrevistados coordenadores de carreiras afins de diferentes casas de estudo, bem como professores de matemática dessas instituições. A análise revelou uma ampla gama de programas de estudo para capacitar professores do ensino fundamental, sem diretrizes gerais e com pouco controle. Na Costa Rica não há regulamentações sobre o propósito, a duração, o perfil ou o conteúdo desses programas, o que poderia afetar 0 ensino da matemática em instituiç̧ões de ensino fundamental, pois os professores chegam com ênfases diferentes em sua formação.

Palavras-chave: ensino da matemática; formação docente; formação universitária; educação primária.

$\mathrm{A}$ ctualmente, las personas crecen y viven saturadas de información que les llega mediante diversos medios y que les provoca un nivel de incertidumbre alto, por tanto, el reto de la formación de estas personas debe dirigirse a la transformación de toda esa información en conocimientos que les ayuden a comprender de mejor manera su entorno (Pérez, 2010).

La sociedad demanda que los docentes sean capaces de facilitar y trasmitir a sus estudiantes, desde la infancia, aprendizajes que les sirvan para la vida, para ser buenos ciudadanos, capaces de seguir aprendiendo por ellos mismos (Muñoz, 2008). Esta tarea se hace cada vez más difícil debido, en parte, a la diferencia que existe entre lo que se abarca en las aulas de educación primaria y lo que sucede en la vida cotidiana de los estudiantes. Muchas veces se da una enseñanza completamente fuera de contexto, con la que el estudiante piensa que lo que ve en la escuela es solo con la finalidad de rendir en exámenes y tareas para pasar de año, pero no interioriza que ese conocimiento lo debe acompañar el resto de su vida, así como debe darle las herramientas para adaptarse exitosamente a la sociedad.
En Costa Rica, los educadores encargados de I y II ciclos de la EGB deben impartir varias asignaturas a un mismo grupo de estudiantes. Generalmente, en el I ciclo imparten las cuatro asignaturas básicas (matemática, español, ciencias y estudios sociales) y en el II algunos imparten solamente dos de ellas, si la escuela en la que trabajan tiene el personal suficiente y así lo consideran (Alpízar, Alfaro, Morales, Ramírez y Salas, 2013).

Un docente que imparte matemáticas, a cualquier nivel, debe ser capaz de proponer actividades a sus estudiantes de acuerdo con los conocimientos previos de estos y en concordancia con el contenido que se quiere enseñar; además, tener un conocimiento especializado en cuanto a lo que va a enseñar (Godino, Batanero, Font y Giacomone, 2016).

Enseñar matemáticas a niños en edad escolar es todo un reto para el docente, ya que este no solo requiere conocer y manejar de manera adecuada los conceptos teóricos de la materia que imparte, sino que su carisma debe revelar el interés porque su pupilo aprenda y se sienta bien. Por ello, las estrategias metodológicas que utilice deben ser 
adecuadas al nivel educativo y contexto de su grupo de estudiantes; esto conlleva que debe tener conocimiento sobre la didáctica específica de la temática por enseñar.

De lo anterior, surge la pregunta: ¿cómo logra un docente el éxito al enseñar matemáticas en la educación primaria? Una de las posibles respuestas sería mediante una adecuada formación profesional universitaria que lo preparara para los retos que debe enfrentar en el aula; asimismo, es preciso que tenga conciencia de que la formación continua y la capacitación permanente son parte de su desarrollo profesional.

A raíz de la respuesta a la pregunta anterior, surge una nueva interrogante: ¿qué debe contener un programa de formación universitaria para docentes de I y II ciclos de la educación general básica (EGB)? El estudio del conocimiento profesional del docente de matemática es un tema el cual se ha trabajado mucho en los últimos años, debido a la importancia que tiene el determinar las particularidades que requiere tener sobre el conocimiento matemático y el pedagógico un docente encargado de impartir dicha asignatura a cualquier nivel de instrucción (Rodríguez-Flores, Picado-Alfaro, Espinoza-González, Rojas-González y Flores-Martínez, 2016).

Existen diversos autores que tratan sobre el conocimiento del docente y establecen modelos para su análisis: Shulman (1986, 1987), Ball, Thames y Phelps (2008), Carrillo, Climent, Contreras, Muñoz-Catalán (2013), entre otros; en el marco teórico de este artículo se hace un acercamiento a algunos de ellos.

Como lo expresa Ruiz (2014), a raíz de los cambios curriculares que se han realizado en los programas de estudio para primaria y secundaria en matemáticas en Costa Rica, el reto más importante que tiene el país es mejorar la preparación de los docentes; ya que ellos son la clave no solo de la implementación curricular, sino también de todo el progreso educativo. Para esto, debe prestarse atención tanto a la capacitación de docentes en servicio como a su formación inicial.

Estudiar y caracterizar el conocimiento que debe tener un docente de educación primaria, para impartir clases de matemáticas es una tarea de suma importancia para fortalecer los programas de formación. Por tal motivo, en esta investigación se da a conocer, de manera general, la formación que están recibiendo los docentes en las aulas universitarias. Cabe destacar que la indagación que se realizó no permite analizar con detalle la enseñanza que reciben directamente en el aula universitaria, ni el énfasis que se le da a los distintos componentes del conocimiento; es decir, si se le da mayor atención al conocimiento del contenido o al conocimiento pedagógico.

En este documento, de modo específico, se pretende hacer una descripción del desarrollo que se da en los programas de formación profesional de los docentes de I y II ciclos de la EGB de Costa Rica, al área de las matemáticas y a su didáctica, con el fin de evidenciar la variedad que existe en el país respecto a los planes de formación de estos docentes.

\section{Marco teórico}

En este apartado, se describen los pilares que dan sustento teórico a la investigación, relacionados con formación docente.

\section{Formación docente}

Vivimos en un mundo en constante cambio y la velocidad de estos es cada vez mayor, la educación no escapa a esta 
realidad, se necesitan docentes formados para los retos actuales, no con los que crecimos hace más de 15 años, como lo expresa Pérez (2010): "si la escuela tiene que responder a nuevas y complejas exigencias, la formación de los docentes ha de afrontar retos similares para responder a tan importantes y novedosos desafíos" (p. 38). La formación docente impartida por las instituciones universitarias debe revisarse y plantearse de acuerdo con estos nuevos desafíos, considerando, entre otros puntos, que la población estudiantil actual maneja los medios tecnológicos y la información que de ellos se desprende de manera natural, el modo en que aprenden ya no es el mismo que diez años atrás, es más dinámico.

Según Llinares (2008), la formación universitaria de los docentes debe enfatizarse en la necesidad de prepararlos para ser profesionales competentes en su área, además de capaces de seguir aprendiendo mientras ejercen su profesión.

Existen varios modelos que intentan dar un acercamiento al tipo de conocimiento que debe tener un docente para impartir clases de matemática, sin importar el nivel de instrucción.

Uno de los precursores de investigaciones relacionadas con el conocimiento profesional que debe tener un docente es Shulman, el cual considera que un profesor debe dominar diversas definiciones y conceptos del área disciplinar, así como relacionar distintos conocimientos de la misma disciplina y otras; además, piensa que debe poder ser capaz de presentar la materia a los estudiantes considerando diversas características de estos, como dificultades, habilidades, entre otros (Shulman, 1986, 1987). En 1986, hace su primera propuesta, en la que define tres categorías sobre el conocimiento que debe tener un docente; a saber: conocimiento del contenido, conocimiento pedagógico del contenido y conocimiento curricular (Shulman, 1986). Para 1987, incluye cuatro categorías más a su modelo: conocimiento pedagógico del contenido, conocimiento de los estudiantes y sus características, conocimiento de los contextos educativos y conocimiento de los fines, propósitos y valores de la educación (Shulman, 1987).

A partir del modelo establecido por Shulman, aparece otro, con el cual se caracteriza el conocimiento del profesor en seis subdominios (Ball, Thames y Phelps, 2008), que ha servido de base para diversas investigaciones y como cimiento para otros modelos con mayor grado de especificidad. En la figura siguiente, se presenta un resumen de dicho modelo conocido como Conocimiento matemático para la enseñanza (MKT).

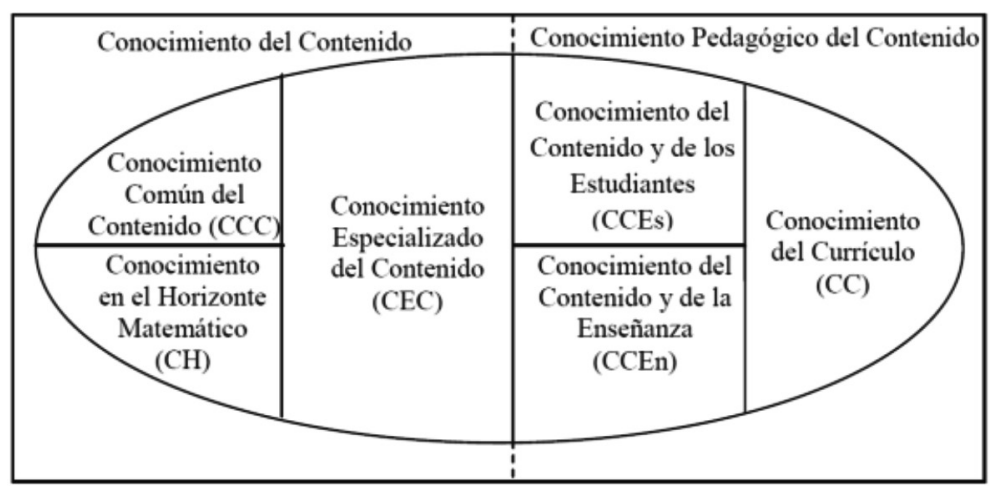

Figura 1. Dominios del Conocimiento matemático para la enseñanza (MKT) (Ball, Thames, Phelps, 2008).

De acuerdo con la información de la figura 1, se puede observar que se hace una división entre el conocimiento del contenido, que enfoca lo referente a las matemáticas, y el conocimiento pedagógico del contenido, referido al proceso de enseñanza 
y aprendizaje de las matemáticas. El primero se subdivide en conocimiento común del contenido (CCC, comprensión de los contenidos que el docente tiene en común con otros profesionales quienes utilizan las matemáticas), conocimiento en el horizonte matemático $(\mathrm{CH}$, comprensión de la relación existente entre los conocimientos de matemáticas con otras áreas del currículo) y conocimiento especializado del contenido (CEC, conocimiento que el docente requiere para enseñar). El segundo se subdivide en conocimiento del contenido y de los estudiantes (CCEs, que permite a los docentes interpretar el pensamiento de sus estudiantes respecto de las tareas y contenidos matemáticos), conocimiento del currículo ( $\mathrm{CC}$, acerca de la propuesta curricular) y conocimiento del contenido y de la enseñanza (CCEn, que mezcla el saber sobre la enseñanza y las matemáticas) (Ball, Thames, Phelps, 2008).

Por tanto, un programa de formación profesional universitario debe prestar atención tanto al conocimiento del contenido como al conocimiento pedagógico del contenido. En el caso particular de esta investigación, los cursos que se desarrollen en el área de las matemáticas en las universidades deben responder a estos dos dominios.

Actualmente, en Costa Rica, no se tiene ninguna regulación para los planes de estudio de carreras que se relacionen con la enseñanza de I y II ciclos de la EGB; es decir, no se regulan los requisitos de entrada, el nombre de la carrera, la cantidad de cursos por cada área temática, el tiempo total de duración de tal carrera o de los cursos particulares (cuatrimestre, semestre), el contenido que debe abarcarse, la especialidad del profesional que imparte cada curso acorde con el plan de estudios, o el tipo de competencias profesionales que debe desarrollar un docente en formación. Esto significa que no se regula ni el conocimiento del contenido ni el pedagógico que se está desarrollando en los docentes en formación, quienes se encargarán, en un futuro próximo, de impartir las clases de matemáticas en la educación primaria. Algunos países sí regulan la titulación de estos docentes, muchos de ellos de origen europeo como España; mientras que, en el continente americano, Ecuador actualmente está organizando la oferta de carreras relacionadas con educación, intentando homogeneizar la formación que reciben (Martínez et al., 2017). En Chile, se cuenta con una serie de estándares tanto pedagógicos como de diversas áreas de las matemáticas, que deben tener los egresados de las carreras relacionadas con la educación básica (Pincheira y Vásquez, 2018).

El Programa experimental de formación de docentes de educación infantil en la Universidad de Málaga, en España, considera que debe haber relación entre la investigación hecha en las universidades y sus resultados, para que estos lleguen a las aulas de la educación básica. Lo anterior supone procurar que los docentes asignados a impartir los cursos universitarios de cada especialidad sean los más pertinentes por su trayectoria investigadora y académica relacionada con el área por enseñar (Pérez, 2010). El formador de formadores debe ser consciente de que no solamente puede quedarse con los conceptos básicos de una asignatura en particular y trasmitirlos a sus aprendices, sino de que debe quedarles a estos últimos, muy claro, el tipo de abordaje metodológico y las estrategias de evaluación que fomentarán aprendizaje en un grupo de estudiantes de primaria, por lo que la preparación requerida para un formador de formadores debe ser amplia, variada y especializada. 
En el caso de las matemáticas, conocer su contenido escolar considerando distintas perspectivas como aplicaciones en la cotidianidad, diversos significados, distintas maneras de representar el mismo contenido es lo que permite al docente tomar decisiones sobre el tipo de actividades que puede desarrollar en su clase, para así generar aprendizaje en sus estudiantes (Llinares, 2009).

El docente actual debe concebir los temas del currículo por enseñar como un conjunto de problemas y situaciones relevantes, disciplinares o interdisciplinares, que retan la capacidad de comprensión y acción de los estudiantes, no como un listado de temas que se entrelazan entre sí que no tienen relación con las situaciones cotidianas. Los conocimientos disciplinares que se desarrollan en la educación formal no deben considerarse un fin en sí mismos, sino convertirse en herramientas útiles en la resolución de los problemas cotidianos que se viven día tras día (Pérez, 2010).

Lo anterior supone que el docente debe permitir que sus estudiantes piensen, establezcan estrategias, aunque estas no sean las correctas, pero que expresen y defiendan sus ideas. Esto no se logra con un aprendizaje basado en el enfoque tradicional, sino que los docentes en formación deben ir creando sus ideales en las aulas universitarias. Por ello, lo trascendental de establecer programas de formación adecuados al currículo oficial y a los cambios sociales que se viven; considerando que es tan importante el conocimiento que este profesional tenga acerca del contenido que enseña, así como los aspectos didácticos o pedagógicos de este. Lo dicho deja en evidencia que el docente formador debe tener la capacidad de fomentar en sus estudiantes el desarrollo de las competencias citadas.
Según Pérez (2010), "los docentes han de formarse como investigadores de su propia práctica, para identificar y regular los recursos implícitos y explícitos que componen sus competencias y cualidades profesionales" (p. 47). Esto indica que no solamente se debe dar un conjunto de contenidos para que el docente los trasmita en su aula en el momento en que ejerza su profesión, sino también es preciso que forme dando diversas herramientas que lo habiliten para autoevaluarse y tomar decisiones al respecto, ya sea que busque actualización y capacitación o cambie procedimientos que está llevando a cabo y no son de utilidad en su misión como educador; es decir, reflexionar sobre su propia práctica.

Pérez (2010) considera que al plantear un programa de formación deben tomarse en cuenta las siguientes cualidades como elementos del perfil de salida del docente en formación:

1) Ser competente para planificar, desarrollar y evaluar la enseñanza de los aprendizajes referidos a una materia, pero además que fomenten el desarrollo de las cualidades humanas de los estudiantes.

2) Crear situaciones flexibles de aprendizaje donde la riqueza cultural y democrática se incentive.

3) Promover su desarrollo profesional, actualizarse frecuentemente, ser capaz de formar comunidades de aprendizaje con sus colegas.

Además de contar con puntos clave en las temáticas por abordar en los diversos cursos, el programa de formación debe poder evaluar a sus estudiantes, de manera formativa o sumativa, ya que dicha evaluación da las herramientas, para distinguir si 
un docente en formación está adquiriendo las competencias o las habilidades necesarias para desarrollarse en su ámbito laboral.

En el New Zealand Teacher Council, se dan algunas sugerencias sobre el contenido que deben tener los procesos de evaluación en los programas de formación inicial; se citan algunos: ser parte integral del proceso de aprendizaje que se ha llevado en las distintas clases; beneficiar y promover el aprendizaje del estudiantado; motivar a los estudiantes para que desarrollen sus habilidades, conocimientos y actitudes, considerando que les serán de provecho para su vida profesional; estimular la reflexión, autoevaluación y coevaluación entre pares; incentivar el aprendizaje cooperativo e individual; ser coherente con la finalidad de cada curso; ser manejable, de acuerdo con el tiempo de trabajo que debe invertirse, y trasparente en los criterios por considerar (Kane, citado en Pérez, 2010).

Por otra parte, para que un docente en formación pueda comprender la razón de ser de su profesión es necesario que tenga intervenciones pedagógicas o prácticas profesionales a lo largo de su formación académica en la universidad, esas intervenciones (prácticas) se realizan en las aulas de primaria, interactuando con docentes en ejercicio y con escolares.

Según Camacho y Rojas (2013), la intervención pedagógica o práctica docente constituye un aspecto importante para los estudiantes de carreras relacionadas con educación, pues es un espacio donde se entremezclan los saberes y los aprendizajes que han adquirido durante su formación académica universitaria.

Cuando los docentes en formación visitan las aulas ponen en práctica los conocimientos adquiridos en los recintos universitarios. Es ahí donde se dan cuenta de que no es suficiente con la teoría abordaba, sino que el contexto y la cotidianidad tienen su cuota de importancia en su labor profesional.

En la Universidad Nacional el proceso de intervención pedagógica pretende que el estudiantado valore no solamente el contenido por desarrollar, según el área de conocimiento, sino también cómo realizará el proceso de mediación, qué conocimientos previos se requieren, las estrategias por utilizar y el momento de emplearlas, así como el uso del contexto del estudiantado (Camacho y Rojas, 2013).

Otra de las áreas en las cuales se debe prestar atención en la formación inicial es en el desarrollo de habilidades para realizar investigación en los contextos escolares, donde se desempeñan (Font y Godino, 2011). No deben ser solamente trasmisores de conocimiento, sino estar en la capacidad de reconocer una situación problemática en su ámbito laboral, conocerla a profundidad, plantear posibles soluciones y evaluarlas; es decir, el docente requiere estar en la capacidad de reflexionar sobre su propia práctica. Durante los años de formación, es preciso que el docente desarrolle las habilidades que le permitan ser crítico de su trabajo y reflexivo acerca de las soluciones que dará a las situaciones adversas con las que puede encontrarse.

Todo programa de formación requiere evaluación periódica, con el fin de establecer sus fortalezas y, también, observar las debilidades o las posibles amenazas que tenga. En Costa Rica, el ente encargado de realizar evaluaciones en las carreras universitarias aprobadas es el Consejo Nacional de Rectores (CONARE), a través de la acreditación de estas, pero no es obligación de las instituciones de educación superior someter a esta evaluación sus carreras, sino que es una decisión propia de la 
institución. Por ello, un número importante de programas de formación no se someten a tal proceso evaluativo.

\section{Metodología}

Esta investigación se puede clasificar como cualitativa de corte descriptivo, ya que pretende dar a conocer una realidad sin intervenir en ella. Se busca hacer una descripción del desarrollo dado en los programas de formación profesional de los docentes de I y II ciclos de la EGB de Costa Rica, al área de las matemáticas y a su didáctica. Esto, con el fin de tener un panorama general de lo que ocurre con la formación profesional de los docentes en ese nivel de instrucción y en esa área particular.

Para cumplir con el propósito investigativo, se hizo una revisión documental de los planes de estudio de las diversas universidades que tienen carreras relacionadas con formación docente de I y II ciclos de la EGB, tanto públicas como privadas. Además, se revisaron los descriptores de los cursos relacionados con el área de las matemáticas. Con base en dichos documentos, se hace una descripción de diversos elementos tales como número de universidades que imparten estas carreras, perfil de salida, duración del bachillerato y de la licenciatura, cantidad de cursos por área del saber, número de créditos, entre otros. En relación con los cursos de matemáticas y su didáctica, se analizaron aspectos como perfil del docente que los imparte, total de créditos relacionados con esta área, temática abordada, metodología y evaluación.

\section{Recolección de datos y participantes}

A continuación, se describen las etapas que se llevaron a cabo en la recolección de los datos y los participantes en cada una de ellas.
Etapa 1: se solicitó información al Consejo Nacional de Educación Superior Privada (CONESUP), el cual es el ente encargado de la aprobación de los programas de estudio de las distintas carreras de las universidades privadas, acerca de las instituciones privadas que tenían aprobadas carreras relacionadas con I y II ciclos de la EGB.

Etapa 2: se contactó a cada universidad, de la lista entregada por el CONESUP, de manera telefónica, personal o por correo electrónico, con el propósito de conocer si para el 2017 tenían activa alguna de las carreras aprobadas por este organismo. En las universidades estatales, se indagó, por medio de sus sitios web, si se ofertaban las carreras de interés para este estudio; solamente se indagó en sedes centrales.

Etapa 3: se realizó una recolección de los planes de estudio de las carreras de interés de las universidades que tenían activa para el 2017 una carrera relacionada con formación básica en I y II ciclos. Dichos programas se obtuvieron por medio de visita personal, correo electrónico, sitio web oficial de la universidad respectiva o se hizo una solicitud al archivo del CONESUP (caso de instituciones privadas).

Etapa 4: se entrevistaron coordinadores de carreras relacionadas con I y II ciclos (coordinadores generales o, en algunos casos, a la directora del área de educación) de diversas universidades, tanto públicas como privadas. El objetivo de estas entrevistas fue detallar aspectos relacionados con el plan de estudios de las carreras afines, como cambios realizados en los últimos cinco años, pertinencia con el currículo de primaria actual del Ministerio de Educación Pública (MEP), entre otros. La mayor parte de las entrevistas se efectúo de manera personal. En la tabla adjunta, se presenta la información de los académicos entrevistados. 
Tabla 1

Encargados de carreras relacionadas con I y II ciclos de la EGB que fueron entrevistados durante el 2017

\begin{tabular}{|c|c|c|c|c|}
\hline Entrevistados & Universidad & $\begin{array}{c}\text { Nombre de los } \\
\text { académicos }\end{array}$ & $\begin{array}{c}\text { Área de } \\
\text { especialización }\end{array}$ & $\begin{array}{c}\text { Tipo de entrevista } \\
\text { Fecha } \\
\end{array}$ \\
\hline & Universidades estatales & & & \\
\hline Entrevistada 1 (E1) & $\begin{array}{l}\text { Universidad de Costa } \\
\text { Rica, Sede Central (UCR) }\end{array}$ & $\begin{array}{l}\text { M. Sc. Yessica Araya } \\
\text { Ramírez } \\
\text { (Coordinadora de carrera) }\end{array}$ & Lingüística & $\begin{array}{l}\text { Entrevista personal } \\
\text { hecha por Marianela } \\
\text { Alpízar } \\
12 \text { de setiembre, } 2017\end{array}$ \\
\hline Entrevistada 2 (E2) & $\begin{array}{l}\text { Universidad Nacional, } \\
\text { Sede Central (UNA) }\end{array}$ & $\begin{array}{l}\text { Licda. Melissa Obando } \\
\text { Santamaría } \\
\text { (Coordinadora de carrera) }\end{array}$ & $\begin{array}{l}\text { Educación } \\
\text { primaria }\end{array}$ & $\begin{array}{l}\text { Entrevista personal } \\
\text { hecha por Marianela } \\
\text { Alpízar } \\
7 \text { de setiembre, } 2017\end{array}$ \\
\hline \multirow[t]{2}{*}{ Entrevistada 3 (E3) } & $\begin{array}{l}\text { Universidad Estatal a } \\
\text { Distancia, Sede Central } \\
\text { (UNED) }\end{array}$ & $\begin{array}{l}\text { M. Sc. María de los } \\
\text { Ángeles Chavarría Román } \\
\text { (Coordinadora de carrera) }\end{array}$ & $\begin{array}{l}\text { Educación } \\
\text { con énfasis en } \\
\text { Currículum. } \\
\text { Especialidad en } \\
\text { Primaria }\end{array}$ & $\begin{array}{l}\text { Entrevista realizada } \\
\text { vía correo electrónico } \\
25 \text { de setiembre, } 2017\end{array}$ \\
\hline & Universidades privadas & & & \\
\hline Entrevistado 4 (E4) & $\begin{array}{l}\text { Universidad Internacional } \\
\text { San Isidro Labrador, Sede } \\
\text { Heredia (UISIL) }\end{array}$ & $\begin{array}{l}\text { Lic. Mario Sánchez } \\
\text { Ugalde } \\
\text { (Coordinador de carrera) }\end{array}$ & $\begin{array}{l}\text { Enseñanza de la } \\
\text { Matemática }\end{array}$ & $\begin{array}{l}\text { Entrevista personal } \\
\text { hecha por Marianela } \\
\text { Alpízar } \\
23 \text { de agosto, } 2017\end{array}$ \\
\hline Entrevistada 5 (E5) & $\begin{array}{l}\text { Universidad Latina, Sede } \\
\text { Heredia }\end{array}$ & $\begin{array}{l}\text { M. Sc. Erika Barrantes } \\
\text { Zúñiga } \\
\text { (Directora de Educación) }\end{array}$ & $\begin{array}{l}\text { Educación infantil } \\
\text { y primaria }\end{array}$ & $\begin{array}{l}\text { Entrevista personal } \\
\text { hecha por Marianela } \\
\text { Alpízar } \\
18 \text { de agosto, } 2017\end{array}$ \\
\hline Entrevistada 6 (E6) & $\begin{array}{l}\text { Universidad Florencio } \\
\text { del Castillo, Sede Heredia } \\
\text { (UCA) }\end{array}$ & $\begin{array}{l}\text { Licda. Ángela María } \\
\text { Chacón Jiménez } \\
\text { (Coordinadora de carrera) }\end{array}$ & $\begin{array}{l}\text { Educación infantil } \\
\text { y primaria }\end{array}$ & $\begin{array}{l}\text { Entrevista realizada } \\
\text { vía correo electrónico } \\
9 \text { de octubre, } 2017\end{array}$ \\
\hline Entrevistada 7 (E7) & $\begin{array}{l}\text { Universidad } \\
\text { Hispanoamericana, Sede } \\
\text { Heredia (UH) }\end{array}$ & $\begin{array}{l}\text { M. Sc. Monserrat Vindas } \\
\text { Cordero } \\
\text { (Decana de la Facultad de } \\
\text { Educación) }\end{array}$ & $\begin{array}{l}\text { Educación } \\
\text { primaria }\end{array}$ & $\begin{array}{l}\text { Entrevista personal } \\
\text { hecha por Ana Lucía } \\
\text { Alfaro } \\
27 \text { de setiembre, } 2017\end{array}$ \\
\hline Entrevistada 8 (E8) & $\begin{array}{l}\text { Universidad } \\
\text { Hispanoamericana, Sede } \\
\text { Heredia (UH) }\end{array}$ & $\begin{array}{l}\text { Licda. Francini De La O } \\
\text { Segura } \\
\text { (Coordinadora de carrera) }\end{array}$ & $\begin{array}{l}\text { Educación } \\
\text { primaria }\end{array}$ & $\begin{array}{l}\text { Entrevista realizada } \\
\text { vía correo electrónico } \\
19 \text { de octubre, } 2017\end{array}$ \\
\hline
\end{tabular}

Etapa 5: se extrajeron, de los planes de estudio de cada universidad, el nombre de los cursos que se imparten relacionados con matemáticas. Para el caso de universidades privadas, se realizó una solicitud al archivo del CONESUP, con la finalidad de obtener el descriptor de dichos cursos, ya que, al hacer la solicitud en algunas universidades, esta fue denegada y en los sitios web de estas no se encuentran. En las universidades estatales, los datos fueron facilitados por correo electrónico o de manera personal por los docentes que imparten los cursos, en la UNA y la UCR, y por medio de la coordinadora de carrera, en la UNED.

Etapa 6: se entrevistaron docentes universitarios encargados de impartir cursos de matemáticas o afines en las carreras de interés para este estudio. El objetivo de dichas entrevistas fue detallar algunos aspectos de estos que no se evidenciaban de manera directa en los programas de estudio, 
ya que en varios solo se contó con el descriptor, el cual no posee el detalle metodológico, ni de instrumentos de evaluación.

En la tabla adjunta, se presenta la información de los académicos entrevistados y la universidad de procedencia. Para el caso de las universidades estatales se consideraron docentes de la sede central y para las privadas, las sedes ubicadas en la provincia de Heredia.

Tabla 2

Docentes que imparten cursos de matemáticas en las carreras relacionadas con I y II ciclos de la EGB, 2017

\begin{tabular}{|c|c|c|c|c|}
\hline Entrevistados & Universidad & $\begin{array}{c}\begin{array}{c}\text { Nombre de los } \\
\text { académicos }\end{array} \\
\end{array}$ & $\begin{array}{c}\text { Área de } \\
\text { especialización }\end{array}$ & $\begin{array}{c}\text { Tipo de entrevista } \\
\text { Fecha } \\
\end{array}$ \\
\hline $\begin{array}{l}\text { Profesora } \\
\text { entrevistada } 1 \text { (PE1) }\end{array}$ & UCR & $\begin{array}{l}\text { Dra. Gabriela Valverde } \\
\text { Soto }\end{array}$ & $\begin{array}{l}\text { Educación Matemática } \\
\text { para Primaria }\end{array}$ & $\begin{array}{l}\text { Entrevista personal hecha } \\
\text { por Marianela Alpízar } \\
14 \text { de julio, } 2017\end{array}$ \\
\hline $\begin{array}{l}\text { Profesora } \\
\text { entrevistada } 2 \text { (PE2) }\end{array}$ & UNA & $\begin{array}{l}\text { M. Ed. Maureen } \\
\text { Camacho Oviedo }\end{array}$ & Educación primaria & $\begin{array}{l}\text { Entrevista personal hecha } \\
\text { por Marianela Alpízar y Ana } \\
\text { Lucía Alfaro } \\
7 \text { de setiembre, } 2017\end{array}$ \\
\hline $\begin{array}{l}\text { Profesora } \\
\text { entrevistada } 3 \text { (PE3) }\end{array}$ & UNA & $\begin{array}{l}\text { Licda. Melissa Obando } \\
\text { Santamaría }\end{array}$ & Educación primaria & $\begin{array}{l}\text { Entrevista personal hecha } \\
\text { por Marianela Alpízar } \\
7 \text { de setiembre, } 2017\end{array}$ \\
\hline $\begin{array}{l}\text { Profesor entrevistado } \\
4 \text { (PE4) }\end{array}$ & UNED & $\begin{array}{l}\text { Dr. Ronald Sequeira } \\
\text { Salazar }\end{array}$ & $\begin{array}{l}\text { Enseñanza de la } \\
\text { Matemática }\end{array}$ & $\begin{array}{l}\text { Entrevista personal hecha } \\
\text { por Dannis Ulate } \\
7 \text { de setiembre, } 2017\end{array}$ \\
\hline $\begin{array}{l}\text { Profesor entrevistado } \\
5 \text { (PE5) }\end{array}$ & UISIL & $\begin{array}{l}\text { Lic. Mario Sánchez } \\
\text { Ugalde }\end{array}$ & $\begin{array}{l}\text { Enseñanza de la } \\
\text { Matemática }\end{array}$ & $\begin{array}{l}\text { Entrevista personal hecha } \\
\text { por Marianela Alpízar } \\
7 \text { de setiembre, } 2017\end{array}$ \\
\hline $\begin{array}{l}\text { Profesora } \\
\text { entrevistada } 6 \text { (PE6) }\end{array}$ & $\mathrm{UCA}$ & $\begin{array}{l}\text { Licda. Lilliana María } \\
\text { Navarro Villegas }\end{array}$ & Educación & $\begin{array}{l}\text { Entrevista realizada vía } \\
\text { correo electrónico } \\
31 \text { de octubre, } 2017\end{array}$ \\
\hline $\begin{array}{l}\text { Profesora } \\
\text { entrevistada } 7 \text { (PE7) }\end{array}$ & $\mathrm{UH}$ & $\begin{array}{l}\text { Licda. Francini De La O } \\
\text { Segura }\end{array}$ & Educación primaria & $\begin{array}{l}\text { Entrevista realizada vía } \\
\text { correo electrónico } \\
19 \text { de octubre, } 2017\end{array}$ \\
\hline $\begin{array}{l}\text { Profesora } \\
\text { entrevistada } 8 \text { (PE8) }\end{array}$ & $\mathrm{UH}$ & $\begin{array}{l}\text { Licda. Ivannia Murillo } \\
\text { Chavarría }\end{array}$ & Educación primaria & $\begin{array}{l}\text { Entrevista realizada vía } \\
\text { correo electrónico } \\
8 \text { de octubre, } 2017\end{array}$ \\
\hline
\end{tabular}

Fuente: Elaboración propia de la investigación.

\section{Descripción de los planes de estudio}

Para el procesamiento de los datos, se consideraron, únicamente, las universidades que para el 2017 tuvieran activa una carrera relacionada con I y II ciclos de la EGB.

Para la descripción de los planes de estudio de las carreras y las universidades seleccionadas, se tomaron en cuenta los siguientes aspectos: grado ofrecido, perfil de salida, años de duración, asignaturas, número de cursos de matemática que ofrecen, creditaje, entre otros.

\section{Descripción de los programas de cur- sos relacionados con matemáticas}

En cuanto a los programas de los cursos relacionados con matemáticas, fueron de interés: creditaje, horas de contacto con el docente, nivel de la carrera donde se imparten los cursos, requisitos, objetivo general, contenidos abordados, metodología, entre otros. 


\section{Resultados y análisis}

En el 2017, según datos suministrados por el CONESUP, 24 universidades privadas tenían aprobada, ante este órgano, al menos una carrera relacionada con docencia en I y II ciclos de la EGB (CONESUP, 2017), información suministrada por medio de correo electrónico); por otra parte, tres universidades estatales, también imparten al menos una carrera relacionada con dicha temática en su sede central. En la tabla adjunta, se presenta el listado de las 27 universidades con el nombre de la(s) carrera(s) aprobada(s) relacionada(s) con educación primaria, en las asignaturas básicas.

Tabla 3

Universidades estatales y privadas con aprobación de carreras profesionales de educación en I y II ciclos de la EGB. Costa Rica, 2017

\begin{tabular}{l}
\hline Universidad \\
\hline Universidad de Costa Rica (UCR) \\
Universidad Nacional (UNA) \\
Universidad Estatal a Distancia \\
(UNED) \\
Universidad de Cartago Florencio del \\
Castillo (UCA) \\
Universidad Hispanoamericana (UH)
\end{tabular}

Carrera

Bachillerato y Licenciatura en Educación Primaria

Bachillerato y Licenciatura en Pedagogía con énfasis en I y II Ciclo de la Educación General Básica con salida lateral de diplomado

Bachillerato y Licenciatura en Educación General Básica I y II

Ciclo con salida lateral de diplomado

Bachillerato y Licenciatura en Ciencias de la Educación con énfasis en I y II Ciclo

Bachillerato y Licenciatura en la enseñanza del I y II Ciclos de la Educación General Básica

(La denominación con la que se conoce la carrera actualmente es distinta al nombre con que fue aprobada la carrera Ciencias de la Educación con énfasis en I y II Ciclos de la Educación General Básica)

Universidad San Isidro Labrador (UISIL) Bachillerato y Licenciatura en Ciencias de la Educación I y II Ciclos

Universidad Adventista de Centroamérica Bachillerato y Licenciatura en Ciencias de la Educación con (UNADECA) énfasis en I y II Ciclo de la Educación General Básica Universidad de las Ciencias y el Arte (UNICA)

Universidad de San José (USJ)

Bachillerato y Licenciatura en Educación con énfasis en I y II Ciclos

Bachillerato en la Enseñanza Primaria con énfasis en Matemáticas

Bachillerato en la Enseñanza Primaria con énfasis en Estudios Sociales

Bachillerato en la Enseñanza Primaria con énfasis en Español Bachillerato en la Enseñanza Primaria con énfasis en Ciencias

Universidad Santa Lucía (USL) Bachillerato y Licenciatura en Ciencias de la Educación con énfasis en I y II Ciclos

Universidad Federada de Costa Rica (San Judas Tadeo) Bachillerato en Ciencias de la Educación con énfasis en I y II Ciclo Licenciatura en Educación I y II Ciclo con énfasis en atención a las necesidades especiales del niño en el aula regular

Universidad Católica de Costa Rica Bachillerato y Licenciatura en Ciencias de la Educación con énfasis en I y II Ciclos de la Educación General Básica 


\begin{tabular}{|c|c|}
\hline Universidad & Carrera \\
\hline Universidad Central (UC) & $\begin{array}{l}\text { Bachillerato y Licenciatura en Ciencias de la Educación con } \\
\text { énfasis en I y II ciclo bilingüe } \\
\text { Bachillerato y Licenciatura en Ciencias de la Educación con } \\
\text { énfasis en I y II Ciclos } \\
\text { Bachillerato en Ciencias de la Educación con énfasis en } \\
\text { la enseñanza de los Estudios Sociales (Español, Ciencias, } \\
\text { Matemáticas) para I y II Ciclos }\end{array}$ \\
\hline $\begin{array}{l}\text { Universidad Libre de Costa Rica } \\
\text { (ULICORI) }\end{array}$ & $\begin{array}{l}\text { Bachillerato y Licenciatura en Ciencias de la Educación con } \\
\text { énfasis en I y II Ciclos }\end{array}$ \\
\hline $\begin{array}{l}\text { Universidad Metropolitana Castro Carazo } \\
\text { (UMCA) }\end{array}$ & $\begin{array}{l}\text { Bachillerato en Ciencias de la Educación con énfasis en I y II } \\
\text { Ciclo }\end{array}$ \\
\hline Universidad de la Salle & $\begin{array}{l}\text { Bachillerato en Ciencias de la Educación con énfasis en I y II } \\
\text { Ciclo Área Ciencias y Matemática } \\
\text { Bachillerato en Ciencias de la Educación con énfasis en I y II } \\
\text { Ciclo Área Español y Estudios Sociales }\end{array}$ \\
\hline Universidad FUNDEPOS Alma Mater & $\begin{array}{l}\text { Bachillerato y Licenciatura en Ciencias de la Educación con } \\
\text { énfasis en I y II Ciclos }\end{array}$ \\
\hline Universidad Fidélitas & $\begin{array}{l}\text { Bachillerato y Licenciatura en la Enseñanza de I y II Ciclos de la } \\
\text { Educación General Básica }\end{array}$ \\
\hline Universidad Americana (UAM) & $\begin{array}{l}\text { Bachillerato y Licenciatura en Ciencias de la Educación con } \\
\text { énfasis en I y II Ciclos }\end{array}$ \\
\hline Universidad Latina & $\begin{array}{l}\text { Bachillerato en Ciencias de la Educación con énfasis en I y II } \\
\text { Ciclos }\end{array}$ \\
\hline $\begin{array}{l}\text { Universidad Autónoma de Centroamérica } \\
\text { (UACA) }\end{array}$ & $\begin{array}{l}\text { Bachillerato y Licenciatura en Ciencias de la Educación con } \\
\text { énfasis en I y II Ciclos }\end{array}$ \\
\hline Universidad Politécnica Internacional & $\begin{array}{l}\text { Bachillerato y Licenciatura en Ciencias de la Educación con } \\
\text { énfasis en I y II Ciclo }\end{array}$ \\
\hline Universidad Independiente & $\begin{array}{l}\text { Bachillerato en Ciencias de la Educación en I y II Ciclo con } \\
\text { énfasis en Español y Estudios Sociales } \\
\text { Bachillerato en Ciencias de la Educación en I y II Ciclo con } \\
\text { énfasis en Ciencias y Matemáticas }\end{array}$ \\
\hline Universidad Metodista & $\begin{array}{l}\text { Bachillerato en Ciencias de la Educación con énfasis en I y II } \\
\text { Ciclos }\end{array}$ \\
\hline $\begin{array}{l}\text { Universidad de las Ciencias Empresariales } \\
\text { (UCEM) }\end{array}$ & $\begin{array}{l}\text { Bachillerato en Ciencias de la Educación para la Enseñanza en I } \\
\text { y II Ciclos Bilingüe }\end{array}$ \\
\hline Universidad Cristiana Internacional (ICU) & $\begin{array}{l}\text { Bachillerato y Licenciatura en Ciencias de la Educación con } \\
\text { énfasis en Formación Docente para I y II Ciclo }\end{array}$ \\
\hline
\end{tabular}

Fuente: Elaboración propia de la investigación con los datos aportados por CONESUP (2017) y la visita a sitios web de las universidades estatales.

Aunque 27 instituciones de educación superior tienen aprobada al menos una carrera, relacionada con este estudio, para el 2017 no todas tienen activa la oferta de esta. Tal información se obtuvo por medio de llamadas telefónicas o correos electrónicos dirigidos a las oficinas administrativas de las diversas universidades. En la tabla adjunta, se enuncian las universidades públicas y privadas que para el 2017 ofertaron al menos una de las carreras. Aquí se hizo diferencia entre bachillerato y licenciatura, ya que el análisis posterior se efectuará según esta clasificación. Cabe destacar que solamente se consideró, para el caso de las universidades estatales, si la carrera era ofrecida en la sede central de estas. 


\section{Tabla 4}

Universidades estatales y privadas que ofrecieron carreras profesionales de educación en I y II ciclos de la EGB costarricense, 2017

\begin{tabular}{|c|c|}
\hline Universidad & Carrera \\
\hline \multirow[t]{2}{*}{$\begin{array}{l}\mathrm{UCR} \\
\mathrm{U}\end{array}$} & Bachillerato en Educación Primaria \\
\hline & Licenciatura en Educación Primaria \\
\hline \multirow[t]{2}{*}{ UNA } & $\begin{array}{l}\text { Bachillerato en Pedagogía con énfasis en I y II Ciclo de la Educación General Básica } \\
\text { con salida lateral de diplomado }\end{array}$ \\
\hline & Licenciatura en Pedagogía con énfasis en I y II Ciclo de la Educación General Básica \\
\hline UNED & $\begin{array}{l}\text { Bachillerato en Educación General Básica I y II Ciclo con salida lateral de diplomado } \\
\text { Licenciatura en Educación General Básica I y II Ciclo }\end{array}$ \\
\hline UCA & $\begin{array}{l}\text { Bachillerato en Ciencias de la Educación con énfasis en I y II Ciclo } \\
\text { Licenciatura en Ciencias de la Educación con énfasis en I y II Ciclo }\end{array}$ \\
\hline UH & $\begin{array}{l}\text { Bachillerato en Ciencias de la Educación con énfasis en I y II Ciclos de la Educación } \\
\text { General Básica } \\
\text { Licenciatura en Ciencias de la Educación con énfasis en I y II Ciclos de la Educación } \\
\text { General Básica }\end{array}$ \\
\hline UISIL & $\begin{array}{l}\text { Bachillerato en Ciencias de la Educación I y II Ciclos } \\
\text { Licenciatura en Ciencias de la Educación I y II Ciclos }\end{array}$ \\
\hline UNADECA & $\begin{array}{l}\text { Bachillerato en Ciencias de la Educación con énfasis en I y II Ciclo de la Educación } \\
\text { General Básica } \\
\text { Licenciatura en Educación con énfasis en I y II Ciclos }\end{array}$ \\
\hline UNICA & $\begin{array}{l}\text { Bachillerato en Educación con énfasis en I y II Ciclos } \\
\text { Licenciatura en Educación con énfasis en I y II Ciclos }\end{array}$ \\
\hline USJ & $\begin{array}{l}\text { Bachillerato en la Enseñanza Primaria con énfasis en Matemáticas } \\
\text { Bachillerato en la Enseñanza Primaria con énfasis en Inglés } \\
\text { Bachillerato en la Enseñanza Primaria con énfasis en Estudios Sociales } \\
\text { Bachillerato en la Enseñanza Primaria con énfasis en Español } \\
\text { Bachillerato en la Enseñanza Primaria con énfasis en Ciencias }\end{array}$ \\
\hline USL & $\begin{array}{l}\text { Bachillerato en Ciencias de la Educación con énfasis en I y II Ciclos } \\
\text { Licenciatura en Ciencias de la Educación con énfasis en I y II Ciclos }\end{array}$ \\
\hline Universidad Federada & $\begin{array}{l}\text { Bachillerato en Educación I y II Ciclo } \\
\text { Licenciatura en Educación I y II Ciclo }\end{array}$ \\
\hline
\end{tabular}

Fuente: Elaboración propia de la investigación con los datos de CONESUP (2017) y consultas directas a cada universidad.

A la UCEM, la Universidad Cristiana Internacional, la Universidad Metodista y la Universidad Independiente no fue posible contactarlas para realizar la consulta, por lo que se eliminaron de este estudio.

Según la E5, la Universidad Latina y la UAM se encontraban realizando un análisis de los planes de estudio de sus carreras relacionadas con el tema en estudio, por lo que no estaban ofertando dichos programas; cabe destacar que la Universidad Latina imparte algunos cursos en Guápiles, para una generación que está por graduarse.

Las carreras en oferta pueden variar de un año a otro, ya que depende de si hay interesados en inscribirse, por tanto, puede que en el 2017 alguna no estuviera impartiéndose, pero para el 2018 o 2019 sí, como es el caso de lo sucedido en la UC; por otra parte, ciertas universidades ya dejaron de ofertar lo que no tiene demanda desde hace algún tiempo, como es el caso de la Universidad Fidélitas. 
De la tabla 4, se desprende que ocho instituciones privadas y tres públicas ofertaron programas relacionados con formación para docentes de I y II ciclos de la EGB en el 2017. Lo anterior representa una disminución respecto a la cantidad de universidades que ofertaban este tipo de carreras en el 2012, según el reporte hecho en Alfaro, Alpízar, Morales, Ramírez y Salas (2013), en el cual indicaron que 15 instituciones privadas impartían carreras afines a las de interés en este estudio.

La E5 sostiene que la disminución de la oferta de estas carreras puede deberse a que algunas universidades se encuentran reestructurando su plan de estudios para estar acordes con los retos actuales, ya que el MEP ha cambiado los programas de estudio de las asignaturas básicas; además, considera que la demanda por estas carreras ha ido disminuyendo.

Por su parte, el E4, coordinador académico de la UISIL, afirma que, a partir del 2015, en esta institución, ha disminuido la cantidad de personas que ingresan a la carrera; hace tres años entraban alrededor de 300 personas y para el 2017, solo 80 . En contraposición, la E6 afirma que en los últimos tres años ha aumentado la matrícula de esta carrera en su institución. En cuanto a las universidades estatales, las coordinadoras de las carreras estudiadas expresan que no ha habido disminución en la cantidad de personas que ingresan cada año. Inclusive, la coordinadora de la UNED manifiesta que hubo un incremento para el caso de esa universidad. Lo anterior puede deberse a que el número de estudiantes que ingresa a cada carrera en una universidad estatal (UNA o UCR) se establece, de manera previa, por la unidad académica a la cual esta pertenece.

Conocer la cantidad de graduados por universidad en los últimos seis años es un componente importante de este estudio, ya que da un panorama del número de profesionales por año en esta área. En la tabla adjunta, se presentan las universidades que en el 2017 tenían carreras de interés activas y se hace un recuento de sus graduados, tanto de bachillerato como de licenciatura. Para la obtención de estos datos, se consultó al CONESUP y a las encargadas de las carreras en las sedes centrales de tales universidades estatales.

Las universidades que han graduado mayor cantidad de bachilleres en el periodo estudiado son la USJ y la UCA; mientras que la USL solamente cuenta con 12 bachilleres en dicho lapso.

En el caso de la licenciatura, la UCA y la UISIL son las que gradúan mayor cantidad. La UCA es de las que más gradúa en ambos grados académicos, pero la UISIL tiene menos del $50 \%$ en la promoción de bachillerato respeto a su licenciatura; según el E4, esto se debe a que muchos estudiantes que inician sus estudios en otras universidades se trasladan para completar la licenciatura en esta, en especial, aquellos provenientes de universidades estatales. Esta misma situación podría estarse presentando en la UNICA y en la USL, ya que la cantidad de graduados en bachillerato es mucho menor a la de licenciatura. En la UH sucede lo contrario, gradúan un número importante de bachilleres, pero en licenciatura no pasan de tres por año, por lo cual es la institución que menos ha graduado en los últimos seis años.

En la USJ, que tiene cinco énfasis distintos en su bachillerato, la mayoría de sus estudiantes se gradúan con énfasis en inglés o español, la menor parte lo hace en matemáticas, con solamente siete estudiantes en el periodo estudiado.

Conocer el contenido de los planes universitarios relacionados con educación en I y II ciclos es uno de los objetivos de este estudio. Cabe destacar que lo estipulado en 
la formulación del plan no siempre coincide con lo que sucede en las aulas; sin embargo, es un indicio del propósito que tiene la casa de enseñanza superior en cuanto a una carrera particular. Algunos de los planes facilitados por el CONESUP tienen más de 20 años de estar aprobados, pero la obtención de estos por otra vía se dificultó, ya que no están evidentes en el sitio web de la universidad respectiva y no fue posible que los facilitaran, aunque se realizó una visita a la institución o se hizo la solicitud vía correo electrónico.
Para realizar la descripción de los programas de estudio de las universidades, se realizó una separación por tipo de universidad (estatal o privada). Valga resaltar que, sin importar la condición de la universidad, no existe en Costa Rica lineamiento alguno que regule el contenido en el programa de formación de carreras que tengan un perfil de salida similar, en cuanto al puesto que van a desempeñar.

Tabla 5

Cantidad de graduados de bachillerato o licenciatura, por año, de las universidades estatales y privadas que ofrecieron carreras profesionales de educación en I y II ciclos de la EGB. Costa Rica, periodo 2012-2017

\begin{tabular}{lcccccccc}
\hline Universidad & Grado de la carrera & $\mathbf{2 0 1 2}$ & $\mathbf{2 0 1 3}$ & $\mathbf{2 0 1 4}$ & $\mathbf{2 0 1 5}$ & $\mathbf{2 0 1 6}$ & $\mathbf{2 0 1 7}$ & Total \\
\hline UCR & Bachillerato & 24 & 10 & 22 & 15 & 20 & 17 & 108 \\
Sede Central & Licenciatura & 13 & 11 & 24 & 1 & 13 & 14 & 76 \\
UNA & Bachillerato & 11 & 18 & 13 & 22 & 22 & SD & 86 \\
& Licenciatura & 17 & 13 & 5 & 10 & 10 & SD & 55 \\
UNED & Bachillerato & & & & & & & \\
USJ & Licenciatura & & & & SD & & & \\
& Bachillerato & & 115 & 89 & 90 & 97 & 143 & 534 \\
UCA & Bachillerato & 36 & 121 & 94 & 100 & 77 & 95 & 523 \\
& Licenciatura & 37 & 106 & 94 & 73 & 58 & 34 & 402 \\
UNICA & Bachillerato & 26 & 31 & 36 & 59 & 46 & 52 & 250 \\
& Licenciatura & 28 & 60 & 66 & 53 & 70 & 64 & 341 \\
UISIL & Bachillerato & 1 & 33 & 43 & 36 & 57 & 59 & 229 \\
& Licenciatura & 18 & 122 & 108 & 94 & 91 & 99 & 532 \\
UH & Bachillerato & 6 & 25 & 13 & 41 & 19 & 51 & 155 \\
& Licenciatura & - & 2 & 1 & 3 & 1 & 2 & 9 \\
UNADECA & Bachillerato & 12 & 6 & 4 & 2 & 3 & 5 & 32 \\
Universidad & Licenciatura & 6 & 4 & 5 & - & 2 & 1 & 18 \\
Federada & Bachillerato & 1 & 4 & 7 & 9 & 7 & 1 & 29 \\
USL & Licenciatura & - & 1 & 5 & 3 & 6 & 5 & 20 \\
& Bachillerato & 1 & 1 & & 4 & 3 & 3 & 12 \\
& Licenciatura & 17 & 62 & 46 & 36 & 46 & 58 & 265 \\
\hline
\end{tabular}

Notas de tabla:

SD: Sin datos.

Fuente: Elaboración propia de la investigación con los datos facilitados por CONESUP (2018), División de Educación Básica de la UNA (2018) y Sección de Educación Primaria de la UCR (2018). 


\section{Planes de estudio Universidades estatales}

Actualmente la UCR, la UNED y la UNA, en sus sedes centrales, ofrecen carreras relacionadas con la temática en estudio en este documento. Todas poseen el bachillerato y la licenciatura; la UNED y la UNA brindan la salida lateral del diplomado, la UCR y la UNA trabajan por ciclos, mientras que la UNED por cuatrimestres.

En cuanto a la duración del plan de estudios, en la UNA se tardan ocho ciclos para completar el bachillerato y dos extra para licenciatura, al igual que en la UCR. El diplomado en la UNA se obtiene con seis ciclos y en la UNED con siete cuatrimestres; en esta última institución, con 12 se alcanza el bachillerato y con tres más licenciatura. Ello indica que, sin importar la universidad estatal por elegir, en tiempo, se tardaría lo mismo en obtener un bachillerato (cuatro años) o los cursos de la licenciatura (cinco años). Para la obtención del grado de licenciatura, en las tres instituciones debe realizarse un trabajo final de graduación y solamente en la UCR se cumple con el TCU (trabajo comunal universitario), el cual consiste en que cada estudiante trabaje 300 horas en alguna acción social para su comunidad.

Los cambios en educación son notorios tanto en el nivel internacional como en el nacional. Cada día hay más investigaciones relacionadas con lo que debe contener un currículo y la formación profesional precisa para los docentes que desarrollan dicho currículo. En la última década, en Costa Rica se han actualizado los programas de estudio de primaria y secundaria de las instituciones bajo la tutela del MEP en diversas áreas del saber, lo cual ha provocado que las casas de educación superior realicen cambios en sus carreras dedicadas a la formación de los profesionales que estarán en las aulas de estos niveles, tal como se describe a continuación.
E2, coordinadora de la carrera en la UNA, indicó que el plan de estudios de $\mathrm{Pe}$ dagogía con énfasis en Iy II Ciclo de la Educación General Básica se encuentra en reformulación, y considera que el cambio que se está realizando es profundo. Lo anterior es apoyado por la PE2; además, ella expresa que las modificaciones al plan de estudios fueron impulsadas por las observaciones hechas por los pares evaluadores del proceso de acreditación en el que se encuentran. En la UCR, el plan vigente de Educación Primaria empezó a regir en el 2016, E1 expresó que se hicieron múltiples cambios en este nuevo plan de estudios, en comparación con el anterior, los cuales consideraron como pilar fundamental el desarrollo profesional de los graduados. E3 indica que, debido al proceso de reacreditación, en la UNED, se encuentran constantemente revisando y reestructurando los diferentes cursos de $E d u$ cación General Básica I y II Ciclo.

Las tres universidades estatales tienen la carrera, considerada en este estudio, acreditada ante el Sistema Nacional de Acreditación de la Educación Superior (SINAES), institución encargada de promover el mejoramiento permanente de la calidad de la educación superior costarricense y la única aprobada por el Estado para la acreditación de las carreras universitarias (SINAES, 2017). Esto indica que cada uno de los planes de estudio ha estado en revisiones continuas y se ha sometido a programas de mejoramiento revisados por pares evaluadores costarricenses y extranjeros.

El principal requisito de ingreso que tienen las carreras en estos centros de formación es el bachillerato en educación media otorgado por el MEP; además, en la UCR y la UNA se aplica un examen de admisión a la universidad. La PE1 expresa que en la UCR se ha discutido acerca de realizar una 
prueba específica para el ingreso a la carrera, pero que aún no llegan a un consenso.

Cada centro de enseñanza superior define un perfil de salida para sus graduados, en el cual considera, entre otros puntos, las competencias profesionales desarrolladas en su plan de estudios. A continuación, se hace una descripción de dichos perfiles por cada universidad.

Según el plan de estudios de la UNA, el graduado en Pedagogía con énfasis en I y II ciclos está capacitado para ocupar diferentes puestos dentro del sistema educativo nacional; entre ellos: docente de I y II ciclo de la EGB, asesor-supervisor del MEP, capacitador y asesor en procesos que involucren elementos pedagógicos relacionados con currículo y evaluación (UNA, 2017).

Por otra parte, se considera que las funciones del egresado se diferencian de acuerdo con los niveles de la carrera. El que egresa de diplomado posee la capacidad de identificar y diagnosticar los aportes de la pedagogía en los procesos educativos en general, así como de desarrollar procesos pedagógicos en las aulas. En el nivel de bachillerato, el profesional podrá ejecutar y promover procesos pedagógicos en general y logrará analizar su propia práctica pedagógica; en el nivel de licenciatura, estará habilitado para construir y formular sus propios proyectos pedagógicos, así como para generar y ejecutar propuestas de evaluación e investigación curricular (UNA, 2017).

Según la E2, en la UNA, además de los conocimientos que se debe tener en las áreas específicas y su didáctica, se le da mucho énfasis a la investigación y al trabajo social, con el fin de que los graduados laboren en la comunidad donde se encuentre su centro educativo y traten de integrar a los padres de familia en las aulas.
La UCR realiza un perfil de salida para el bachillerato y otro para la licenciatura, así como considera en cada uno conocimientos y habilidades que debe tener el graduado. Además, toma en cuenta un listado de actitudes y valores, sin importar el nivel del estudiante. A continuación, se realiza un extracto de la información ubicada en la Reestructuración Integral del Plan de Estudio de la Carrera de Bachillerato y Licenciatura en Educación Primaria (2014).

Entre los conocimientos para los graduados de bachillerato, están los relacionados con las tareas propias de un docente en el aula, planeamiento, mediación pedagógica, evaluación, siempre consideradas bajo un nivel de reflexión acerca de lo que se hace. Esto implica un conocimiento exhaustivo del currículo oficial del MEP para las diversas áreas. Además, el graduado debe saber acerca del contexto económico y social del país, estar en la capacidad de autoaprender y utilizar la tecnología de manera efectiva; permanecer al tanto de los cambios biológicos del ser humano y de la neuroeducación.

En cuanto al nivel de licenciatura, se agrega la caracterización del entorno educativo (urbano, rural, la escuela unidocente); el conocimiento de la realidad educativa; diseñar y ejecutar procesos de investigación; incorporar, en la toma de decisiones pedagógicas y profesionales, el aporte de la sociología, la psicología, la neurociencia, entre otras, como parte de los procesos de reflexión-acción del quehacer educativo.

La E1 comentó que la carrera de la UCR tiene como enfoque curricular el sociocrítico, por lo que su graduado está en la capacidad de detectar las debilidades y las fortalezas de sus estudiantes y, a través de la investigación (investigación-acción) y reflexión, aquel puede planear su labor $\mathrm{y}$ establecer acciones para atender esas 
debilidades. El profesional en esta área debe saber que la investigación no es un requisito académico para obtener un grado, sino que una actividad permanente en su labor.

En cuanto a la UNED el propósito de su carrera es:

La formación del profesional docente, enfatizando los procesos de enseñanza y aprendizaje, de manera individual y grupal. [...] El plan de estudios les brinda a los futuros educadores los conocimientos teóricos, metodológicos, pedagógicos y psicológicos que se requieren para la atención de los estudiantes de I y II ciclos. Les ofrece estrategias que permiten la construcción del conocimiento, así como la adquisición de destrezas hacia una eficaz acción pedagógica, transmitiendo a los futuros educadores los medios para "aprender a aprender" y resolver los conflictos tanto cognitivos como de las necesidades y adversidades del entorno inmediato en el cual están inmersos los educandos (UNED, 2018, párr. 10).

Según la E3, los graduados de la UNED son docentes con capacidad de autonomía, de resolución de conflictos, de investigar para innovar y de fácil adaptación, ya que el desarrollo cotidiano de la enseñanza se encuentra filtrando cambios con la velocidad y la dinámica dignos de la sociedad del conocimiento y de la información; por lo que entiende que es necesaria la formación permanente y constante.

Como campo laboral de la mayoría de los graduados de estas carreras, sin importar la universidad de procedencia, se encuentra trabajar como docente de I y II ciclos de la EGB, tanto en el ámbito privado como en el público. El mayor empleador en este campo es el MEP.

Al realizar una comparación entre los perfiles de salida de las diversas universidades, se encuentra que, en el caso de la UNA y la UCR, se hace énfasis en el perfil que tendrá el graduado en cada una de las etapas de la carrera: bachillerato y licenciatura; se hace evidente que, mientras avanza en la carrera, así debe ser su nivel de análisis de las situaciones que se le presenten en el aula y con ello poder ser un investigador en su área. En cuanto a la UNED, no se hace diferencia por título y su énfasis está más orientado a la labor que realiza el docente en el aula.

Las tres coordinadoras entrevistadas coinciden en que la investigación es un pilar fundamental en la formación de un docente, ya que esta contribuirá en su trabajo de aula; por ende, está presente en el perfil de salida en las tres casas de enseñanza (E1, E2 y E3).

Si se compara el perfil de salida de cada universidad con lo expuesto por Pérez (2010) en el marco teórico de este artículo, se pueden identificar varias similitudes, entre ellas, que el docente no solo requiere manejar muy bien aspectos pedagógicos y didácticos, sino que debe hacerle frente a la situación social en la que se va a desenvolver; además de que la investigación y la actualización en un formador son aspectos fundamentales. Asimismo, de acuerdo con lo expuesto por estos perfiles de salida y las opiniones externadas por las coordinadoras respectivas, en las aulas universitarias se está trabajando tanto el conocimiento del contenido como el conocimiento pedagógico del contenido, al estar desarrollando aspectos teóricos específicos de cada área temática, en conjunto con sus elementos didácticos, lo cual está incluido en el modelo MKT de Ball, Thames y Phelps (2008). 
Por otra parte, no se puede esperar hasta que el docente en formación se gradúe para que tenga contacto con las aulas de primaria; el poner en práctica los conocimientos universitarios es fundamental. Es por ello que se realiza la práctica profesional (se conoce con nombres distintos, según la universidad), mediante la que los docentes en formación deben adentrarse a las aulas e impartir lecciones a escolares bajo la tutela de profesores universitarios y colaboradores que se desarrollan en la educación primaria. Cabe destacar que, en varios cursos de los distintos planes de estudio, los estudiantes van a las aulas a realizar observaciones o pequeñas intervenciones; sin embargo, solo se reportarán aquí los cursos exclusivos de práctica docente.

Para el caso de la UCR, se establece un curso de práctica docente en el octavo semestre, este se encuentra en paralelo con un seminario relacionado con ella. En la UNA, según la E2, el curso Construcción pedagógica desde el aula escolar, ubicado en el cuarto semestre, es el correspondiente a dicha práctica de aula para diplomado y los cursos Aprendizaje en el aula escolar, de tercer nivel, y Proyecto Educativo de aula en I y II Ciclos, de cuarto nivel, corresponden a la práctica para bachillerato. En la UNED, deben aprobarse dos cursos relacionados con la práctica docente, el primero en el segundo año para diplomado y el segundo en el cuarto año para el bachillerato.

Tal como lo expresa E3, se debe hacer énfasis en que el nuevo docente requiere involucrarse, desde los primeros años de formación, con el campo laboral donde se desempeñará, razón por la cual, desde el presente plan de estudios, en la UNED, se le da gran importancia a la práctica docente como eje transversal de formación. Esta opinión es secundada por las otras dos coordinadoras de las carreras tratadas en este apartado.

No existe en Costa Rica una legislación que indique la cantidad de cursos por área de conocimiento, ni la orientación de estos en la carrera docente de I y II ciclos de la EGB, por lo que es importante conocer aspectos generales de las áreas en las que cada universidad pone énfasis. A continuación, se hace una distribución de los cursos que están presentes en la malla curricular de cada una de las carreras estudiadas, bajo una clasificación propia de las encargadas de esta investigación. Es pertinente mencionar que dicha clasificación se realizó de acuerdo con la naturaleza de los cursos, según su nombre, por lo que la precisión al categorizarlos es limitada. Se adjunta una tabla con la clasificación hecha y la palabra clave con la que se utilizará dicha categoría en adelante (se usa esta tanto para universidades privadas como públicas). 
Tabla 6

Clasificación, por área temática, de los cursos impartidos en las universidades

\begin{tabular}{|c|c|}
\hline Temáticas consideradas en los cursos & Temática \\
\hline $\begin{array}{l}\text { 1. Pedagogía, didáctica general, psicología, educación, sistema educativo, } \\
\text { administración y gestión educativa, legislación, ética, evaluación, planeamiento, } \\
\text { educación rural, escuelas unidocentes, educación para jóvenes y adultos, desarrollo } \\
\text { infantil, neurociencia, necesidades educativas especiales, innovación educativa, } \\
\text { metodologías de enseñanza. }\end{array}$ & Educación \\
\hline $\begin{array}{l}\text { 2. Materias básicas (español, estudios sociales, ciencias), se consideraron aquí cursos } \\
\text { de didáctica específica. }\end{array}$ & Básicas \\
\hline 3. Matemáticas, se consideraron aquí cursos de didáctica específica y estadística. & Matemáticas \\
\hline 4. Práctica docente & Práctica \\
\hline 5. Investigación & Investigación \\
\hline 6. Herramientas tecnológicas & Tecnología \\
\hline 7. Otros (idiomas, estudios generales, optativas, deportiva, arte, cultura ambiental, etc.) & Otros \\
\hline
\end{tabular}

Fuente: Elaboración propia de la investigación.

Para efectos de la información que se desprende en las siguientes tablas, es importante definir el concepto de crédito, ya que en Costa Rica es la manera de medir el costo de una carrera y las horas que se dedican a esta. Según CONARE (Consejo Nacional de Rectores), ente encargado de aprobar la creación o la modificación de las carreras de las universidades estatales, el crédito es una unidad valorativa del trabajo del estudiante que equivale a tres horas reloj semanales de trabajo, durante 15 semanas, aplicadas a una actividad que ha sido supervisada, evaluada y aprobada por el profesor (CONARE, 2013).

Por otra parte, CONARE establece que el número de créditos para obtener un bachillerato universitario oscila entre 120 y 144, y para completar la licenciatura se requieren de 30 a 36 créditos adicionales (Ruiz, Barrantes y Gamboa, 2009).

Tabla 7

Clasificación de los cursos recibidos en cada uno de los planes de estudio de las universidades estatales, en el nivel de bachillerato. Costa Rica, 2017

\begin{tabular}{lcccccccccccc}
\hline \multicolumn{1}{c}{ Cursos } & \multicolumn{4}{c}{ UCR } & \multicolumn{4}{c}{ UNED } & \multicolumn{4}{c}{ UNA } \\
& $\mathbf{C C}$ & $\mathbf{\%}$ & $\mathbf{C C r}$ & $\mathbf{\%}$ & $\mathbf{C C}$ & $\mathbf{\%}$ & $\mathbf{C C r}$ & $\mathbf{\%}$ & $\mathbf{C C}$ & $\boldsymbol{\%}$ & $\mathbf{C C r}$ & $\mathbf{\%}$ \\
\hline Educación & 19 & 40,4 & 54 & 38,0 & 17 & 40,5 & 51 & 36,4 & 15 & 38,5 & 54 & 38,8 \\
Básicas & 10 & 21,3 & 29 & 20,4 & 8 & 19,0 & 32 & 22,9 & 7 & 17,9 & 24 & 17,3 \\
Matemáticas & 4 & 8,5 & 12 & 8,5 & 3 & 7,1 & 9 & 6,4 & 2 & 5,1 & 7 & 5,0 \\
Práctica & 2 & 4,3 & 8 & 5,6 & 2 & 4,8 & 12 & 8,6 & 3 & 7,7 & 14 & 10,1 \\
Investigación & 2 & 4,3 & 7 & 4,9 & 2 & 4,8 & 6 & 4,3 & 2 & 5,1 & 8 & 5,8 \\
Tecnología & 2 & 4,3 & 6 & 4,2 & 2 & 4,8 & 6 & 4,3 & 1 & 2,6 & 4 & 2,9 \\
Otros & 8 & 17,0 & 26 & 18,3 & 8 & 19,0 & 24 & 17,1 & 9 & 23,1 & 28 & 20,1 \\
Total & 47 & 100 & 142 & 100 & 42 & 100 & 140 & 100 & 39 & 100 & 139 & 100 \\
\hline
\end{tabular}

Notas de la tabla:

CC: Cantidad de cursos.

CCr: Cantidad de créditos.

Fuente: Elaboración propia de la investigación con los datos expuestos en las mallas curriculares de las universidades estatales en los sitios web respectivos. 
De la tabla anterior, se desprende que la UCR es la universidad con mayor cantidad de cursos para obtener el bachillerato, así como el mayor creditaje. Al tratarse de carreras relacionadas con educación, era de esperarse que el componente de cursos de educación tanto general como infantil tuviera un peso importante en la malla curricular, alrededor de $40 \%$ de los cursos caben en esta categoría en las tres universidades (la UNA es la del menor porcentaje).

En cursos relacionados con tecnología, es la UNED la que cuenta con la mayor cantidad. Se consideran cursos en esta categoría, si su nombre lo cita, pero cabe destacar que algunos abordan temas relacionados con tecnología sin que su nombre lo indique.

La UNA dedica tres de sus cursos a la práctica docente, por lo que es la universidad que más invierte en esa temática; sin embargo, es importante destacar que las tres coordinadoras entrevistadas afirman que no solo en esos cursos el estudiante tiene contacto con el aula de educación primaria; ya que desde las primeras clases los estudiantes deben realizar observaciones de aula e impartir algunas lecciones antes de su práctica formal (E1, E2 y E3).

El porcentaje de créditos para las materias básicas es mayor en la UNED, puesto que $29,3 \%$ se dedica a cursos relacionados con matemáticas, ciencias, estudios sociales, español y la didáctica de estas. En cuanto al área específica de matemática, es la UCR que dedica mayor porcentaje de créditos y número de cursos; la UNA solamente cuenta con dos.

Respecto al área de investigación, el peso de los cursos es similar en los planes de estudio de las tres universidades; sin embargo, sobresale que las tres coordinadoras entrevistadas afirmaron que la investigación es un pilar fundamental en sus planes de estudio, desde los primeros niveles de la carrera, en diversos cursos de esta, aunque el nombre del curso no refleje ese detalle (E1, E2 y E3).

En la siguiente tabla, se presenta la distribución de los cursos para licenciatura.

Tabla 8

Clasificación de los cursos recibidos en cada uno de los planes de estudio de las universidades estatales, en el nivel de licenciatura. Costa Rica, 2017

\begin{tabular}{lcccccccccccc}
\hline \multicolumn{1}{c}{ Curso } & \multicolumn{4}{c}{ UCR } & \multicolumn{4}{c}{ UNED } & \multicolumn{4}{c}{ UNA } \\
& $\mathbf{C C}$ & $\mathbf{\%}$ & $\mathbf{C C}$ & $\mathbf{\%}$ & $\mathbf{C C}$ & $\mathbf{\%}$ & $\mathbf{C C r}$ & $\mathbf{\%}$ & $\mathbf{C C}$ & $\boldsymbol{\%}$ & $\mathbf{C C r}$ & $\mathbf{\%}$ \\
\hline Educación & 6 & 54,55 & 18 & 50,0 & 6 & 60,00 & 18 & 60,0 & 6 & 60,00 & 22 & 61,1 \\
Investigación & 3 & 27,27 & 12 & 33,3 & 3 & 30,00 & 9 & 30,0 & 3 & 30,00 & 11 & 30,6 \\
Otros & 2 & 18,18 & 6 & 16,7 & 0 & 0,00 & 0 & 0,0 & 1 & 10,00 & 3 & 8,3 \\
Total & 11 & 100 & 36 & 100 & 10 & 100 & 30 & 100 & 10 & 100 & 36 & 100 \\
\hline
\end{tabular}

Notas de la tabla:

CC: Cantidad de cursos.

CCr: Cantidad de créditos.

Fuente: Elaboración propia de la investigación con los datos expuestos en las mallas curriculares de las universidades estatales en sus sitios web.

Al igual que para el bachillerato, la UCR es la que tiene la mayor cantidad de cursos. Una de las diferencias encontradas es que la UNED solo dedica créditos de licenciatura a materias de educación e investigación. Así como en bachillerato, el peso que se le da a cursos de investigación es similar en las tres universidades. Valga destacar que en la UNED se considera un curso específico de estadística aplicado a la educación, que se clasificó como parte de los cursos de investigación. 
De acuerdo con el análisis de la maya curricular, únicamente la UCR dedica cursos a la educación rural, escuelas unidocentes, educación para jóvenes y adultos. Esta orientación se da en los cursos de la licenciatura; sin embargo, la E2 expresó que la segunda intervención pedagógica (práctica docente) de los estudiantes de la UNA pueden realizarla con adultos y en espacios distintos a las aulas de educación primaria con niños.

Del análisis de la información de las tablas anteriores se desprende que en las universidades estatales se les dan pesos similares a las diversas áreas presentes en un programa de formación docente; no obstante, el enfoque de los cursos de esas áreas podría ser diverso, así como los requisitos que tienen para el personal que imparte los cursos de las distintas especialidades.
En esta investigación, es de gran interés el área de las matemáticas entre los programas de formación, por ende, a continuación, se dedica un apartado al análisis de estos.

\section{Cursos de matemáticas}

En la tabla adjunta, se presenta la información relacionada con las matemáticas en los programas de formación de docentes de primaria de las universidades estatales, se considera el creditaje y las horas contacto que tiene el grupo de estudiantes con el docente a cargo de impartir dicho curso, cabe destacar que por la naturaleza de la UNED, los cursos no cuentan con la clasificación de horas contacto; además del tiempo en las clases se considera la cantidad de tiempo a dedicar fuera de la clase y por tanto el total se da entre las horas contacto y las de estudio independiente.

Tabla 9

Cursos ofrecidos por las universidades estatales, relacionados con el área de las matemáticas. Costa Rica, año 2017

\begin{tabular}{|c|c|c|c|}
\hline Universidad & Cursos ofrecidos (código y nombre) & $\begin{array}{c}\text { Horas contacto } \\
\text { (horas totales) }\end{array}$ & Créditos \\
\hline \multirow{5}{*}{ UCR } & FD-0401 Matemática en la Educación Primaria I* & $4(9)$ & 3 \\
\hline & FD-0515 Matemática en la Educación Primaria II* & $4(9)$ & 3 \\
\hline & FD0259 Matemática en la Educación Primaria III & $4(9)$ & 3 \\
\hline & $\begin{array}{l}\text { FD-0264 Seminario: Investigación en didáctica de la } \\
\text { matemática en la etapa escolar }\end{array}$ & $4(9)$ & 3 \\
\hline & Total & 16(36) & 12 \\
\hline \multirow[t]{4}{*}{ UNED } & 00809 Matemática I para I y II Ciclos* & & 3 \\
\hline & 00810 Matemática II para I y II Ciclos* & & 3 \\
\hline & 02102 Matemática III para I y II Ciclos* & & 3 \\
\hline & Total & & 9 \\
\hline \multirow[t]{3}{*}{ UNA } & $\begin{array}{l}\text { DBJ209 Didáctica de la Matemática para la Educación } \\
\text { Básica* }\end{array}$ & $6(8)$ & 3 \\
\hline & $\begin{array}{l}\text { DBJ402 Didáctica de las Ciencias y las Matemáticas } \\
\text { para la Educación Básica* }\end{array}$ & $7(11)$ & 4 \\
\hline & Total & $13(19)$ & 7 \\
\hline
\end{tabular}

Observaciones para la tabla:

Los cursos marcados con $(*)$ son los que se cuenta con el programa respectivo.

Fuente: Elaboración propia de la investigación con los datos expuestos en las mallas curriculares de las universidades estatales y en sus programas de cursos. 
En cuanto a cantidad de cursos la UCR destina la mayor con cuatro y la UNA con solamente dos; además el curso DBJ402 de la UNA no solo se destina a tópicos de matemáticas y educación matemática, sino que abarca el área de ciencias naturales.

El creditaje en los cursos relacionados con matemáticas oscila entre $3(89 \%$ de los cursos) y 4, donde se mezcla la didáctica de la matemática y las ciencias; en la UNA es donde se otorga mayor cantidad de tiempo en horas contacto para un curso de 4 créditos; sin embargo, las horas con el docente son solamente 4; las otras 3 corresponden al trabajo que hace el estudiante en observaciones $\mathrm{u}$ otras asignaciones en el aula de primaria (PE2), por lo que el tiempo con el docente universitario, es uniforme en las dos instituciones. En el caso de la UNED no se puede realizar un análisis por hora contacto y se encuentra con un creditaje intermedio en comparación con las otras dos universidades.

Existe diversidad respecto a cada universidad en relación con el enfoque que se le da a cada curso; PE1 expresa que la UCR reparte las áreas temáticas que establecen los Programas de Estudio del MEP entre los diversos cursos que imparten; mientras que PE3 afirma que en la UNA se trabajan dichas áreas en el primero de ellos, ya que en el segundo se hace la integración de matemáticas y ciencias, en la UNED se comienza con los conceptos del primer ciclo de la EGB y luego los del II ciclo (PE4).

Todos los formadores entrevistados coinciden en que deben repasar muchos conceptos básicos de matemáticas en sus cursos, debido a que los estudiantes traen bases deficientes de secundaria, por lo que deben dedicar tiempo para abordar temáticas elementales que debían dominar, como operaciones básicas en el conjunto de los números racionales (PE1, PE2, PE3 y PE4). Es evidente aquí que los docentes formadores reconocen que el conocimiento especializado es importante, por ende, no solo enfatizan en el conocimiento pedagógico, sino que tratan de abarcar el del contenido; sin embargo, esto hace reflexionar acerca de si es suficiente el tiempo y la cantidad de cursos que se le está dedicando al área de las matemáticas en los distintos recintos universitarios.

En cuanto al perfil del académico que imparte los cursos relacionados con matemáticas, en la UCR, debe tener formación propia del área, es decir ser graduado en enseñanza de la matemática y vinculado con educación primaria, ya sea tener un título que lo acredite en I y II ciclos de la EGB o demostrar su relación con estos ciclos con investigación (PE1), de manera similar ocurre en la UNED (PE4), mientras que en la UNA debe ser educador de primaria con experiencia en las aulas de este nivel, sin tener formación en matemáticas. Para el caso de la UNA este hecho puede tener consecuencias en la formación de los docentes en cuanto al conocimiento del contenido específico que debe tener, ya que deberían al menos dominar los conceptos que se enseñan en educación primaria, pero no solo de manera procedimental, sino que comprendiendo su estructura conceptual, ya que así como los destaca Llinares (2009), el conocer sobre los diversos significados y representaciones de un concepto hace que sea más fácil encontrar la manera de enseñarlo bajo diversos enfoques.

PE1 expresa que antes del 2005, los cursos relacionados con matemáticas en la UCR estaban más orientados a la adquisición de contenidos básicos de dicha asignatura, a partir de ese año se comenzaron a revisar, para orientarlos más a los cursos que debe recibir 
un docente, que va a impartir clases de matemáticas y se prestó especial atención a la investigación en educación matemática.

En la UNED los cursos han venido cambiando desde que se aprobaron los Programas de Estudio de Matemática del MEP, ya que se han ido ajustando a lo que establecen dichos programas (PE4). Mientras que PE2 y PE3 expresan que en este momento se están haciendo reestructuraciones en el plan de estudios de la carrera en la UNA.

A continuación, se describen algunos de los cursos impartidos, se hace énfasis en aspectos como: propósito del curso, metodología empleada, evaluación y la bibliografía sugerida.

En la UCR, el curso FD-0401 Matemática en la Educación Primaria I, tiene como propósito proporcionar al estudiante herramientas teóricas y prácticas que le faciliten la construcción de conocimientos para la enseñanza y el aprendizaje de los contenidos de los bloques: Números, Relaciones y Álgebra, del I y II ciclo de la EGB (UCR, curso FD-0401, 2017).

PE1 expresa que el objetivo del curso, aparte de profundizar en el contenido matemático (matemática muy básica), se trabaja sobre qué es, cómo se define, cómo se conceptualiza, cómo se representa y las múltiples representaciones del concepto, para qué se usa y para qué sirve.

Dentro de los objetivos generales del curso se encuentran: construir significados y relaciones matemáticas para los contenidos incluidos, desarrollar habilidades que le permitan al estudiantado incorporar en su futura práctica profesional distintas estrategias metodológicas, para atender las diferencias individuales de los escolares en su proceso de aprendizaje de las matemáticas y utilizar diferentes recursos didácticos como herramientas que pueden favorecer el proceso de aprendizaje de la matemática escolar.

Dentro de las estrategias metodológicas que se siguen están: exposición de temas por parte del docente o estudiantes, análisis y aplicación de la teoría presente en diversas lecturas, uso de recursos tecnológicos y materiales didácticos, y trabajo colaborativo.

Generalmente, se arranca la clase discutiendo acerca de dónde se usan ciertos conceptos, por ejemplo, los Números Naturales: cómo y dónde se usan, donde están presentes, etc. Para luego llegar al conjunto en sí, como un sistema con sus propiedades, con las operaciones, con lo que lo rige y tratar un poco de ahondar de qué sirve esto a un docente de primaria, cómo lo va a usar (PE1).

Es importante dejarle claro al docente en formación que la manera en la que se desarrollan las temáticas en el curso universitario, no necesariamente es como van a ir a dar clases a los niños de educación primaria, aquí se dan los fundamentos teóricos y ellos deben reflexionar acerca de su labor en el aula, se trata de que el docente en formación desarrolle las habilidades básicas necesarias que abarquen los conceptos matemáticos y del papel que ellos tendrán al enseñar estos mismos conceptos (PE1).

En cuanto a la evaluación del curso se trabajaron: tres pruebas parciales (de desarrollo), un taller de material didáctico (en grupos, presentaban un recurso didáctico y el uso que se le podría dar), análisis de producciones de escolares, prácticas y asignaciones cortas y la asistencia e informe de la actividad extracurricular (UCR, curso FD0401 2017, PE1).

En cuanto a la bibliografía presente en el programa del curso, se puede notar que todos los documentos se relacionan con matemática educativa en diversos temas $\mathrm{y}$, por 
el título de estos, se distingue que la mayoría son dirigidos para educación primaria.

En cuanto al curso FD-0515 Matemática en la Educación Primaria II, el propósito es proporcionar al estudiante herramientas teóricas y prácticas que le faciliten la construcción de conocimientos para la enseñanza y el aprendizaje de los contenidos de los bloques Geometría y Medidas del I y II Ciclo de la EGB (UCR, curso FD-0515, 2017).

Dentro de los objetivos generales se encuentran: construir significados y relaciones matemáticas para los contenidos de los bloques citados, desarrollar habilidades que le permitan al estudiantado incorporar en su futura práctica profesional distintas estrategias metodológicas, para atender las diferencias individuales de los escolares en su proceso de aprendizaje y utilizar diferentes recursos didácticos como herramientas que pueden favorecer el proceso de aprendizaje de la matemática escolar.

Dentro de las estrategias metodológicas que se siguen están: exposición de temas por parte del docente o estudiante, guías de trabajo grupal e individual para cada tema, debates, uso de herramientas tecnológicas y trabajo colaborativo.

PE1 expresa que al igual que en el curso anterior, se busca que el estudiante reflexione acerca de lo que será su papel en el aula de educación primaria.

En cuanto a la evaluación del curso se trabajan: dos pruebas parciales, actividades prácticas escritas (individuales o grupales), elaboración e implementación de un taller de material didáctico, cinco pruebas cortas individuales (pueden ser comprobaciones de lecturas), lo anterior puede variar de un año a otro, ya que es labor del docente formador elegir la manera en que va a evaluar (UCR, curso FD-0515, 2017). Al igual que el curso anterior la bibliografía recomendada se relaciona con matemáticas y educación para primaria.

Los cursos FD0259 Matemática en la Educación Primaria III y FD-0264 Seminario: Investigación en didáctica de la matemática en la etapa escolar, al momento de la entrevista no se habían ofrecido, por lo que se prefiere no describirlos.

Como se mencionó anteriormente, la UCR es la universidad que cuenta con la mayor cantidad de cursos relacionados con matemáticas en su malla curricular, estos han venido teniendo cambios desde 2005, estos al igual que la carrera toman como corriente central la pedagogía crítica. Se trabajan aspectos teóricos propios de la asignatura (conceptos básicos de matemáticas), así como didácticos, para el nivel de primaria. La evaluación planteada es variable, ya que considera exámenes individuales donde se aplican los contenidos abordados, ya sean matemáticos o didácticos, también, se enfatiza en análisis de trabajos hechos por niños de primaria y se da importancia a la creación de material didáctico con propósito. Lo anterior deja ver que los cursos están planteados para que el docente en formación desarrolle tanto el conocimiento del contenido específico de la asignatura que va a enseñar, así como los aspectos pedagógicos que requiere para tener un buen desempeño en su clase.

Por su parte, en la UNA se imparten los cursos DBJ209 Didáctica de la Matemática para la Educación Básica y DBJ402 Didáctica de las Ciencias y las Matemáticas para la Educación Básica.

En cuanto al curso DBJ209, su objetivo general es identificar el proceso de evaluación como un componente fundamental en la planificación curricular, mediante la integración teórica y el análisis de la praxis pedagógica, para reflexionar sobre la 
importancia del docente como facilitador e investigador en los espacios educativos. Dentro de las temáticas tratadas se citan de manera general, sin vínculo con ninguna de las áreas disciplinares de las matemáticas; sin embargo, en el espacio de estrategia metodológica a desarrollar, se indica que los docentes en formación deben salir de este curso manejando las temáticas que están contenidas en los Programas de Estudio del área de Matemáticas de la EGB. Se promueve una metodología participativa e investigativa, uno de sus referentes teóricos es historia de las matemáticas y sus características como parte del currículo escolar (UNA, curso DBJ209, 2017).

PE3 afirma que en este curso se debe hacer un recuento de conceptos matemáticos que los docentes en formación no recuerdan; por ejemplo, operaciones básicas con números decimales.

En las clases se trata de reproducir el modelo metodológico que estipula el MEP, es decir, al inicio de la temática se les plantea un problema o se les proyecta un video o alguna actividad, para después trabajar en grupos y al final realizar las plenarias, esa forma de trabajar les gusta mucho a los docentes en formación. Para cada sesión se establece una agenda de trabajo y se trata de que las clases sean muy participativas, donde las actividades dinámicas y los juegos cobren un papel fundamental (PE3).

Durante el curso los estudiantes deben hacer observaciones de aula a diversos niveles de la EGB, con la intensión de que ellos conozcan la realidad que se da en las clases de educación primaria y luego puedan plantear una clase (PE3).

En cuanto a las estrategias de evaluación se tienen de manera individual: participación personal, productos de análisis de lecturas, portafolio de estrategias, pruebas cortas; actividades grupales: construcción, aplicación y exposición de una propuesta educativa, tipo taller, según los lineamientos del MEP, observaciones en espacios escolares y su respectivo reporte escrito, exposición de estrategia metodológica, participación y aplicación de temática de expertos en legopedia (UNA, curso DBJ209, 2017).

En cuanto a la bibliografía citada, no se encuentran muchos materiales relacionados con didáctica de la matemática en primaria sino una bibliografía general de educación.

En el curso DBJ402, se mezcla la didáctica de las ciencias y la de las matemáticas. El objetivo general es reflexionar sobre la mediación pedagógica de las ciencias naturales y las matemáticas en el I y II ciclos de la EGB, mediante su aplicación en diversos escenarios y logrando una visión de integralidad (UNA, curso DBJ402, 2017), como requisito para matricular el curso deben tenerse aprobados Didáctica de las Ciencias para la Educación Básica y Didáctica de las Matemáticas para la Educación Básica.

En este curso se abarca, como parte de los contenidos, los Programas de Estudio del MEP vigente de ambas asignaturas, por tanto, ahí se retoman las temáticas que deben ir a enseñar los docentes en formación de las dos áreas del saber. PE2 expresa que por las deficiencias que traen los estudiantes, al ingresar a la universidad, en conceptos básicos de matemáticas, se debe invertir tiempo del curso en afianzar ese conocimiento, ya que un docente no puede enseñar lo que no sabe.

En cuanto a las estrategias metodológicas que se utilizan en las clases, PE3 expresa que al ser dos asignaturas las que deben cubrirse y ambas han sufrido modificaciones en los currículos del MEP, se tiene que distribuir el tiempo para tratar de abarcar lo máximo posible, se debe prestar 
atención a la fundamentación de ambos Programas de Estudio (matemáticas y ciencias); además se abarcan temáticas como diseño curricular, evaluación, perfil del docente, líneas filosóficas en la educación, por ejemplo el racionalismo, etc. Se trabajan escenarios donde se presentan posibles formas de abordar una temática en el aula.

Muchas veces los docentes en formación tienen apatía hacia las matemáticas lo que hace que al llegar a las aulas de primaria se trasmita a los niños, por lo que en las clases se trata de abordar este aspecto, insistiendo en que las matemáticas son de utilidad en la vida cotidiana y como pueden trasmitirle esto a sus estudiantes en el aula (PE3).

Los rubros de evaluación sumativa para este curso son: curiosidad (científica, tecnológica o matemática), experiencias de aula, proyectos de escenarios pedagógicos alternativos (desarrollo ambiental, identidad nacional, ciudadanía digital), investigación y exposición grupal y propuesta metodológica (UNA, curso DBJ402, 2017). Este es el único curso estudiado, que no cuenta con pruebas escritas en su evaluación.

En cuanto a la lista de materiales bibliográficos, mezcla de temáticas de educación en general, ciencias naturales y educación matemática.

En la UNA es donde se cuenta con la menor cantidad de cursos dedicados al área de las matemáticas; aunado a que uno de ellos trata no solo de matemáticas, sino de ciencias naturales, esta situación puede ser preocupante ya que las temáticas a abarcar son muchas y el tiempo escaso, si se desea como lo dicta el perfil de salida de los estudiantes de esta carrera, que los graduados tengan las competencias necesarias para impartir las clases de esta asignatura en I y II ciclos de la EGB, es decir que manejen tanto aspectos pedagógicos del contenido como el contenido mismo.

En cuanto a los cursos ofrecidos por la UNED el objetivo de Matemática I para I y II ciclos es que el estudiante adquiera conocimientos acerca de contenidos básicos afines a los sistemas de numeración, números naturales, teoría de números y números racionales, de manera tal que el docente pueda crear e incorporar actividades que contribuyan a la transformación de la práctica pedagógica y de las realidades educativas.

El objetivo de Matemática II es que el estudiante adquiera los contenidos básicos del sistema métrico decimal y estadística y al igual que en el I, pueda crear actividades y recursos para usar en el aula de primaria.

Matemática III para I y II ciclos pretende que el estudiante conozca y aplique los diferentes contenidos teóricos y metodológicos para la enseñanza y el aprendizaje de los conceptos de la geometría, a partir de procesos constructivos que relacionan los contenidos con situaciones de la vida cotidiana, en forma lógica, crítica y creativa; y nuevamente que pueda mediar de manera adecuada esos conocimientos en las aulas de primaria.

La información anterior fue extraída de los descriptores de los cursos aportados por la coordinadora de la carrera, cabe rescatar que estos no cuentan con la descripción de la metodología ni de la evaluación.

Según PE4 los cursos impartidos por la UNED en el área de matemáticas, tratan de hacer un equilibrio entre las bases teóricas de la asignatura y los aspectos didácticos, ya que el futuro docente debe tener dominio de ambos aspectos; además, que pueda realizar una buena mediación pedagógica con el uso de medios tecnológicos. Aunque, el área de relaciones y álgebra no aparece de manera explícita en ninguno de 
estos, PE4 afirma que dentro de los materiales didácticos que utilizan para impartirlos sí se desarrollan todas las áreas que considera el currículo actual del MEP.

En cuanto a la metodología y la evaluación, por la naturaleza de la universidad los estudiantes realizan muchas actividades en la plataforma virtual; sin embargo, también se hacen pruebas escritas (PE4).

A manera de comparación, la universidad que menor cantidad de cursos ofrece relacionados con matemática es la UNA y la que cuenta con mayor cantidad es la UCR. En la UNA no se requiere que el docente de estos cursos tenga formación en esta área del saber, sino que debe ser docente de I y II ciclos, de preferencia haber estado recientemente impartiendo clases en las aulas de educación primaria. La evaluación sumativa es diversa, al igual que las estrategias metodológicas que se utilizan, el trabajo en grupos es una de las utilizadas y la elaboración de materiales didácticos, para su futura labor docente, también. Solamente, en uno de los cursos abordados en la UNA no se realizan pruebas escritas.

Todos los docentes formadores entrevistados coinciden en que los estudiantes que matriculan los cursos de matemáticas tienen algunos vacíos respecto a conocimientos disciplinarios básicos que se abordaron en educación primaria y secundaria, y que por tanto deben destinar tiempo en hacer repasos, que en la formulación de los cursos universitarios no estaba contemplado. Lo que preocupa al respecto es que no se cuenta en el país con un estándar de lo que debe conocer un docente de primaria en el área de las matemáticas, para impartir clases de esta asignatura en dicho nivel educativo, por lo que algunas universidades ponen énfasis en ciertas áreas temáticas; mientras que las otras lo hacen en aspectos distintos. Pueden encontrarse cambios significativos, inclusive dentro de una universidad, en el mismo semestre se imparten dos grupos del mismo curso y se dan abordajes distintos (PE3).

Por otra parte, se establece que los docentes en formación deben conocer aspectos de las matemáticas que pareciera no traerse como conocimiento previo, lo que podría estar indicando a los encargados de carreras de I y II ciclos de la EGB que es necesaria una formulación en sus cursos, donde se puedan abordar estos tópicos, sin dejar de lado el componente didáctico que se requiere en la formación de sus profesionales; además realizar una valoración en cuanto al tiempo que se le está dedicando al desarrollo profesional en el área de las matemáticas, ya que la diferencia de dos cursos entre una universidad a otra es notoria en cuanto a los elementos que pueden cubrirse.

\section{Universidades privadas}

Las universidades privadas participantes en este estudio organizan su currículo por medio de cuatrimestres. El bachillerato universitario, en una carrera afín a I y II ciclos de la EGB fue ofertado en 2017, por las universidades: UCA, UH, UISIL, UNADECA, UNICA, USJ, USL y la U Federada, en todas, la duración es de ocho cuatrimestres. $\mathrm{La}$ licenciatura la ofrecieron: UCA, UH, UISIL, UNADECA, UNICA, USL y la Federada, la duración de esta es variable, puede tardar desde dos hasta tres cuatrimestres.

Para el ingreso a la carrera el requisito se limita al título de Bachillerato en Enseñanza Media y realizar los trámites administrativos respectivos.

A continuación, se realizará una comparación entre los planes de estudio ofrecidos por las distintas universidades privadas. La información se obtuvo de documentos 
aportados por el CONESUP (mallas curriculares y programas de cursos), los sitios web de las diversas universidades (planes de estudio, mallas curriculares y programas de cursos), los documentos facilitados por las coordinaciones académicas (planes de estudio, mallas curriculares, programas de cursos) y las entrevistas realizadas a coordinadores y docentes.

Cabe destacar que algunos de los planes de estudio reportados en esta investigación estaban en revisión, tal es el caso de la UCA (E6), la UH (E7) y la UISIL (E4), por lo que en 2018 alguna información pudo haber cambiado.

Existen diversas razones por las cuales un programa de formación debe revisarse, en cuanto a la UCA, la directora de la carrera expresó que el plan de estudios de Ciencias de la Educación con Énfasis en I y II ciclos, se encuentra en revisión debido a que mostraba evidencias de que los programas de los cursos estaban desactualizados en cuanto a los contenidos y la metodología presentes en el currículo del MEP (E6). E7 expresó que la carrera Bachillerato y Licenciatura en Primero y Segundo Ciclos de la EGB de la UH tuvo su inicio en 1998 y hasta la fecha están haciendo cambios para enviarlo a su respectiva aprobación con CONESUP, los cambios obedecen, principalmente, a la actualización de las temáticas tratadas en los cursos.

Por su parte, E4 señala que la carrera Ciencias de la Educación con Énfasis en Primer y Segundo Ciclo de la UISIL, se ha visto envuelta en un proceso de revisión, en el área de matemáticas, a partir del cambio del currículo del MEP, se ha prestado especial atención a aspectos metodológicos y uso de recursos tecnológicos.

En cuanto a la comparación del perfil de salida se consideraron las universidades: UCA, UH, UNADECA, USL, USJ, U Federada, debido a que en el programa de estudio obtenido de cada una de estas se pudo encontrar la evidencia respectiva. En todas las universidades consideran que su graduado se podrá desempeñar de manera idónea en las aulas de instituciones de primaria, ya sean públicas o privadas, en la tabla adjunta se citan algunos aspectos particulares del perfil de salida por institución.

Tabla 10

Aspectos citados en el perfil de salida de las diversas universidades privadas que participan en el estudio. Costa Rica, año 2017

\begin{tabular}{ll}
\hline \multicolumn{1}{c}{ Universidades } & \multicolumn{1}{c}{ Aspecto considerado en el perfil de salida } \\
\hline UH & $\begin{array}{l}\text { Utiliza tecnología en las aulas regulares. Elabora materiales } \\
\text { educativos y puede laborar planificando, realizando y dirigiendo } \\
\text { proyectos de investigación educativa. } \\
\text { Profesional responsable con cualidades de liderazgo, buena } \\
\text { comunicación oral, escrita e interpersonal y facilidad para trabajar en } \\
\text { equipo. } \\
\text { USJ } \\
\text { Desarrolla diversas habilidades en los escolares (sociales, } \\
\text { psicoafectivas, cognoscitivas). } \\
\text { Detecta los problemas de los alumnos y el conocimiento de sí } \\
\text { mismo. } \\
\text { UCA, USL, USJ } \\
\text { UCA, USL, UNADECA, U Federada } \\
\text { Es consciente de su labor en el aula que no solo trasmite, sino que } \\
\text { guía al aprendizaje. Que conoce y puede adecuar el currículo. }\end{array}$ \\
\hline
\end{tabular}

Fuente: Elaboración propia de la investigación con los datos expuestos en los programas de formación de cada universidad. 
Se puede observar que la mayor parte de las universidades estudiadas considera como perfil de salida de sus graduados el hecho de que no es solamente un trasmisor de conocimientos en el aula, sino que debe ser consiente que es un guía en el proceso de enseñanza y aprendizaje de las matemáticas y que para ello, debe conocer lo estipulado en el currículo del MEP y adecuarlo a su labor de aula.

Afianzando lo anterior, E4 expresa que se pretende que el docente formado sea un profesional capaz de asumir los retos vigentes en el área de educación, que no solamente pueda trasmitir conocimientos a sus estudiantes, sino que los enseñe a usarlos para resolver problemas en contexto. Cabe aclarar que el perfil de la UISIL no se encuentra en la documentación que se pudo obtener, por ello se agrega la opinión dada por su coordinador en este tema.

En cuanto a aspectos tecnológicos y de investigación solamente la UH hace referencia de manera explícita. En cuanto a desarrollar en los estudiantes de educación primaria habilidades sociales, solamente la USJ y la USL lo retoman. Es importante destacar que la información que se está describiendo aquí es la presente en la documentación que se pudo conseguir de las fuentes citadas antes, por lo que puede haber detalles que no se consideren en este reporte; por otra parte, aunque no se escriba de manera explícita en el perfil de salida puede que en la práctica si se considere.

Cabe destacar que dentro de los perfiles de salida es muy evidente el manejo pedagógico del contenido que se establece como idóneo en un graduado, en una de las carreras de interés; pero no es tan evidente el manejo del contenido teórico de la asignatura.

\section{Formación recibida}

En la Tabla 11 se presenta la distribución de cursos por temáticas, si se quiere ver en detalle la distribución de las temáticas debe consultarse la Tabla 6 .

Tabla 11

Clasificación de los cursos recibidos en cada uno de los planes de estudio de universidades privadas en el nivel de bachillerato. Costa Rica, año 2017

\begin{tabular}{lccccccccc}
\hline \multicolumn{1}{c}{ Temáticas } & & \multicolumn{1}{c}{ Universidad } \\
& UH & USL & UCA & Federada & UNICA & USJ(E) & USJ(M) & UISIL & UNADECA \\
\hline Educación & 14 & 16 & 13 & 13 & 13 & 15 & 15 & 17 & 15 \\
Básicas & 7 & 8 & 5 & 6 & 7 & 12 & 3 & 8 & 8 \\
Matemáticas & 2 & 2 & 2 & 2 & 3 & 1 & 10 & 2 & 4 \\
Práctica & 1 & 1 & 1 & 2 & 1 & 1 & 1 & 2 & 2 \\
Tecnología & 1 & 2 & 2 & 1 & 2 & 1 & 1 & 2 & 2 \\
Investigación & 1 & 0 & 1 & 1 & 1 & 0 & 0 & 1 & 1 \\
Otros & 3 & 3 & 8 & 7 & 6 & 3 & 3 & 7 & 15 \\
Total & $\mathbf{2 9}$ & $\mathbf{3 2}$ & $\mathbf{3 2}$ & $\mathbf{3 2}$ & $\mathbf{3 3}$ & $\mathbf{3 4}$ & $\mathbf{3 4}$ & $\mathbf{3 9}$ & $\mathbf{4 7}$ \\
\hline
\end{tabular}

Notas de la tabla:

La USJ aparece dos veces ya que esta trabaja en diversos énfasis, la primera columna donde aparece corresponde a la distribución del énfasis de español y la segunda el énfasis en matemáticas.

Fuente: Elaboración propia de la investigación con los datos expuestos en las mallas curriculares de las universidades privadas en los sitios web respectivos o facilitados por CONESUP. 
De la tabla anterior se desprende que la universidad con la menor cantidad de cursos para obtener el bachillerato es la $\mathrm{UH}$, mientras que la UNADECA es la que cuenta con mayor número, cabe destacar que, en el caso de esta última de los cursos categorizados en la temática de Otros, nueve se relacionan con religión. Sin considerar la UNADECA, el promedio de cursos es de 33, una cantidad menor a la ofrecida por las universidades estatales para el bachillerato, ya que la que menor ofrece es la UNED con 39.

Todas las universidades cuentan con al menos un curso de práctica docente, el cual se encuentra en el VIII cuatrimestre, aquellos programas que cuentan con dos

cursos se encuentran en el VII y VIII cuatrimestres respectivamente, las universidades que tienen dos cursos de estas temáticas son: UISIL, UNADECA y FEDERADA.

En el caso de la USJ ofrece un tronco común de cinco cuatrimestres y luego están los énfasis de matemáticas, ciencias, español o estudios sociales; por tanto la distribución de los cursos de materias básicas es más alto comparado con los otros; sin embargo, cuando se elige un énfasis se recibe más cantidad de cursos en esa área del saber, pero el número de estos en las otras áreas disminuye. En la tabla que sigue se hace una distribución de los cursos por temática de manera porcentual.

Tabla 12

Distribución porcentual de los cursos recibidos en cada uno de los planes de estudio de universidades privadas en el nivel de bachillerato según temática. Costa Rica, año 2017

\begin{tabular}{lccccccccc}
\hline \multicolumn{1}{c}{ Temáticas } & \multicolumn{10}{c}{$\begin{array}{c}\text { Universidad } \\
\end{array}$} & UH & USL & UCA & Federada & UNICA & USJ(E) & USJ(M) & UISIL & UNADECA \\
\hline Educación & 48,3 & 50,0 & 40,6 & 40,6 & 39,4 & 44,1 & 44,1 & 43,6 & 31,9 \\
Básicas & 24,1 & 25,0 & 6,3 & 18,8 & 21,2 & 35,3 & 8,8 & 20,5 & 17,0 \\
Matemáticas & 6,9 & 6,3 & 3,1 & 6,3 & 9,1 & 2,9 & 29,4 & 5,1 & 8,5 \\
Práctica & 3,4 & 3,1 & 15,6 & 6,3 & 3,0 & 2,9 & 2,9 & 5,1 & 4,3 \\
Tecnología & 3,4 & 6,3 & 6,3 & 3,1 & 6,1 & 2,9 & 2,9 & 5,1 & 4,3 \\
Investigación & 3,4 & 0,0 & 3,1 & 3,1 & 3,0 & 0,0 & 0,0 & 2,6 & 2,1 \\
Otros & 10,3 & 9,4 & 25,0 & 21,9 & 18,2 & 8,8 & 8,8 & 17,9 & 31,9 \\
Total (\%) & $\mathbf{1 0 0}$ & $\mathbf{1 0 0}$ & $\mathbf{1 0 0}$ & $\mathbf{1 0 0}$ & $\mathbf{1 0 0}$ & $\mathbf{1 0 0}$ & $\mathbf{1 0 0}$ & $\mathbf{1 0 0}$ & $\mathbf{1 0 0}$ \\
\hline
\end{tabular}

Fuente: Elaboración propia de la investigación con los datos expuestos en las mallas curriculares de las universidades privadas en los sitios web respectivos o facilitados por CONESUP.

La universidad que destina el mayor peso a los cursos de educación general o infantil es la USL con $50 \%$, mientras que la UNADECA lo hace en menor medida con $31,9 \%$, existen 18 puntos porcentuales de diferencia entre estas, sin embargo; si se compara la cantidad de cursos en el área de educación no es mucha la diferencia, la USL tiene 16 y la UNADECA 15; al igual que en las universidades públicas, el mayor peso se le da a las temáticas relacionadas con educación.

En cuanto a herramientas tecnológicas, todas las universidades destinan al menos un curso en sus mallas curriculares.

La universidad que destina el menor peso en materias básicas (español, estudios sociales, ciencias y matemáticas) es la UCA con $21,9 \%$, mientras que la USJ destina el mayor con alrededor de $38 \%$; este último caso se da porque se cuentan los cursos del 
énfasis específico; sino se considera la USJ, la universidad que da mayor cantidad de peso a las materias básicas es la UNICA con $31,3 \%$, el caso de matemáticas se tratará de manera detallada más adelante.

En la tabla anterior se hace la distribución para el título de bachillerato universitario, donde no necesariamente se debe concluir con una investigación, pero al ser carreras relacionadas con educación este componente se hace indispensable para un profesional en dicha área, la USL y la USJ no dedican ningún curso a esta temática particular en el nivel de bachillerato, cabe destacar que esto no descarta que en otros espacios se retome la temática, pero como curso específico no es evidente en su malla curricular. El componente investigativo es muy importante para un docente en formación, ya que permite que dicho profesional reflexione sobre su práctica y pueda determinar los elementos donde debe mejorar.

El número o porcentaje de cursos en cada área temática no es suficiente para la comparación entre las universidades, por tanto, en la siguiente tabla se hace una descripción considerando el creditaje destinado.

Tabla 13

Clasificación de la cantidad de créditos recibidos en cada uno de los planes de estudio de universidades privadas en el nivel de bachillerato. Costa Rica, año 2017

\begin{tabular}{|c|c|c|c|c|c|c|c|c|c|c|c|c|c|c|c|c|c|c|}
\hline \multirow[t]{3}{*}{ Temáticas } & \multicolumn{18}{|c|}{ Universidades } \\
\hline & \multicolumn{2}{|c|}{ UNADECA } & \multicolumn{2}{|c|}{ UNICA } & \multicolumn{2}{|c|}{ USL } & \multicolumn{2}{|c|}{ Federada } & \multicolumn{2}{|c|}{ UCA } & \multicolumn{2}{|c|}{ USJ(M) } & \multicolumn{2}{|c|}{ USJ(E) } & \multicolumn{2}{|c|}{ UH } & \multicolumn{2}{|c|}{ UISIL } \\
\hline & $\mathrm{CCr}$ & $\%$ & $\mathrm{CCr}$ & $\%$ & $\mathrm{CCr}$ & $\%$ & $\mathrm{CCr}$ & $\%$ & $\mathrm{CCr}$ & $\%$ & $\mathrm{CCr}$ & $\%$ & $\mathrm{CCr}$ & $\%$ & $\mathrm{CCr}$ & $\%$ & $\mathrm{CCr}$ & $\%$ \\
\hline Educación & 45 & 31,9 & 52 & 40,0 & 64 & 50,0 & 52 & 40,6 & 52 & 40,6 & 50 & 39,4 & 50 & 40,0 & 56 & 46,7 & 52 & 43,3 \\
\hline Básicas & 24 & 17,0 & 26 & 20,0 & 32 & 25,0 & 24 & 18,8 & 20 & 15,6 & 15 & 11,8 & 50 & 40,0 & 28 & 23,3 & 24 & 20,0 \\
\hline Matemáticas & 12 & 8,5 & 12 & 9,2 & 8 & 6,3 & 8 & 6,3 & 8 & 6,3 & 42 & 33,1 & 5 & 4,0 & 8 & 6,7 & 6 & 5,0 \\
\hline Práctica & 8 & 5,7 & 4 & 3,1 & 4 & 3,1 & 10 & 7,8 & 4 & 3,1 & 6 & 4,7 & 6 & 4,8 & 4 & 3,3 & 8 & 6,7 \\
\hline Tecnología & 6 & 4,3 & 8 & 6,2 & 8 & 6,3 & 4 & 3,1 & 8 & 6,3 & 3 & 2,4 & 3 & 2,4 & 4 & 3,3 & 6 & 5,0 \\
\hline Investigación & 3 & 2,1 & 4 & 3,1 & & 0,0 & 4 & 3,1 & 4 & 3,1 & & 0,0 & & 0,0 & 4 & 3,3 & 3 & 2,5 \\
\hline Otros & 43 & 30,5 & 24 & 18,5 & 12 & 9,4 & 26 & 20,3 & 32 & 25,0 & 11 & 8,7 & 11 & 8,8 & 12 & 10,0 & 21 & 17,5 \\
\hline $\begin{array}{l}\text { Pruebas de } \\
\text { grado }\end{array}$ & & & & & & & & & & & & & & & 4 & 3,3 & & 0,0 \\
\hline $\begin{array}{l}\text { Total de } \\
\text { créditos }\end{array}$ & 141 & 100 & 130 & 100 & 128 & 100 & 128 & 100 & 128 & 100 & 127 & 100 & 125 & 100 & 120 & 100 & 120 & 100 \\
\hline
\end{tabular}

Fuente: Elaboración propia de la investigación con los datos expuestos en las mallas curriculares de las universidades privadas en los sitios web respectivos o facilitados por CONESUP.

La universidad con mayor cantidad de créditos en su programa de bachillerato es la UNADECA con 141, mientras que la UH y la UISIL presentan la menor cantidad con 120. Lo anterior indica que todos los programas de estudio cuentan con el creditaje sugerido por el CONARE para un bachillerato universitario.

La universidad que dedica mayor porcentaje de créditos al área de educación es la USL, mientras que la UNADECA es la que menos peso le da a esta área, con 18 puntos porcentuales de diferencia, el resto de las instituciones ronda el $40 \%$, al ser este porcentaje mayor a los correspondientes de las universidades estatales. En cuanto a las herramientas tecnológicas la UCA, UNICA y USL le invierten 8 créditos de su plan de estudio, el mayor valor. 
En cuanto a las materias básicas, para el caso de la USJ depende del énfasis que elijan los docentes en formación, por ejemplo si dicho énfasis es en español, se puede observar que 40 créditos son destinados a esta área del saber lo que representa $32 \%$ del total; mientras que para estudios sociales, ciencias y matemáticas se destinan únicamente 5 créditos por cada una; por otra parte, si tiene el énfasis de matemática el porcentaje de créditos dedicados a esa área es de $33,1 \%$ y para el resto de materias básicas $11,8 \%$. Con este aspecto lo que preocupa es que en Costa Rica, en el sector público, el mayor ente empleador es el MEP, y este no hace distinción en la especialidad de los títulos para educación primaria, esto quiere decir que una persona graduada en el énfasis de español puede ser contratada, en la educación primaria, para impartir todas las materias básicas, por lo que tendría una desventaja en sus conocimientos respecto con los graduados de otros programas, donde le dan el mismo peso a cada una de las materias básicas.
Al descartar a la USJ por sus énfasis, se puede observar que la universidad que dedica menor porcentaje de créditos a las materias básicas (incluida matemáticas) es la UCA con $21,9 \%$ mientras que la USL destina $31,3 \%$ a estas mismas temáticas.

La universidad Federada es la que da mayor peso a la Práctica docente con 10 créditos que representan $7,8 \%$ en su malla curricular. En cuanto a la categoría Otros existe mucha variabilidad en el peso que cada universidad le da, mientras que la USJ destina menos de $10 \%$ a esas otras temáticas, la UNADECA más de $30 \%$, donde 35 $\%$ de estos créditos están relacionados con materias sobre religión. Únicamente, la UH presenta en el nivel de bachillerato pruebas de grado con creditaje asignado, representado un 3,3\% de su malla.

En las tablas siguientes se presenta la descripción de cursos y créditos por área temática que considera cada institución de educación superior en el nivel de licenciatura, cabe destacar que se descarta para este análisis la USJ; ya que no cuenta con una oferta de este grado en I y II ciclos exclusivamente.

Tabla 14

Clasificación de los cursos recibidos en cada uno de los planes de estudio de universidades privadas estudiados en el nivel de licenciatura. Costa Rica, año 2017

\begin{tabular}{|c|c|c|c|c|c|c|c|c|c|c|c|c|c|c|}
\hline \multirow[t]{3}{*}{ Temáticas } & \multicolumn{14}{|c|}{ Universidad } \\
\hline & \multicolumn{2}{|c|}{ Federada } & \multicolumn{2}{|c|}{ UH } & \multicolumn{2}{|c|}{ UISIL } & \multicolumn{2}{|c|}{ UNADECA } & \multicolumn{2}{|c|}{ UNICA } & \multicolumn{2}{|c|}{ UCA } & \multicolumn{2}{|c|}{ USL } \\
\hline & $\mathrm{CC}$ & $\%$ & $\mathrm{CC}$ & $\%$ & $\mathrm{CC}$ & $\%$ & $\mathrm{CC}$ & $\%$ & $\mathrm{CC}$ & $\%$ & $\mathrm{CC}$ & $\%$ & $\mathrm{CC}$ & $\%$ \\
\hline Educación & 5 & 41,7 & 6 & 50,0 & 8 & 80,0 & 8 & 80,0 & 4 & 50,0 & 5 & 62,5 & 4 & 57,1 \\
\hline Básicas & 2 & 16,7 & 1 & 8,3 & & 0,0 & & 0,0 & 1 & 12,5 & & 0,0 & & 0,0 \\
\hline Matemáticas & 1 & 8,3 & & 0,0 & & 0,0 & & 0,0 & & 0,0 & & 0,0 & & 0,0 \\
\hline Práctica & & & & & & & & & & & 1 & 12,5 & & \\
\hline Tecnología & & 0,0 & 1 & 8,3 & & 0,0 & & 0,0 & & 0,0 & & 0,0 & 1 & 14,3 \\
\hline Investigación & 2 & 16,7 & 1 & 8,3 & 2 & 20,0 & 1 & 10,0 & 1 & 12,5 & 1 & 12,5 & 1 & 14,3 \\
\hline Otros & 2 & 16,7 & 3 & 25,0 & & 0,0 & 1 & 10,0 & 2 & 25,0 & 1 & 12,5 & 1 & 14,3 \\
\hline Total & 12 & 100 & 12 & 100 & 10 & 100 & 10 & 100 & 8 & 100 & 8 & 100 & 7 & 100 \\
\hline
\end{tabular}

Fuente: Elaboración propia de la investigación con los datos expuestos en las mallas curriculares de las universidades privadas en los sitios web respectivos o facilitados por CONESUP. 
Todas las universidades destinan la mayor parte de los cursos de licenciatura a la temática educación, las que dedican el mayor porcentaje son la UISIL y la UNADECA con $80 \%$ del total de cursos y la que menos destina es la Federada con solamente $41,7 \%$, la Federada es la que dedica la mayor cantidad a Investigación y esta misma es la que tiene la mayor variabilidad en las distintas temáticas, ya que en el nivel de licenciatura cuenta con cursos en cinco de las siete categorías, mientras la UISIL solamente en dos de estas.

En el nivel de licenciatura es muy importante el componente de investigación debido a que se espera que el docente en formación pueda plantearse problemas referentes a su práctica profesional y tengan las herramientas para encontrarles solución; es decir que reflexionen sobre el trabajo que están realizando, solamente la UISIL y la Federada destinan dos cursos a dicho componente, las demás, solamente uno.
La duración de la licenciatura en la UH y la Federada es tres cuatrimestres cada una, son las más extensas, las demás tardan dos. Cabe destacar que ese tiempo se destina a aprobar los cursos referentes al nivel de licenciatura, al acabar estos, en todos los programas indagados, el estudiante debe realizar un trabajo final de graduación, en algunos casos pueden elegir entre realizar una investigación o pruebas de grado; y en otros solamente es válida una opción como en la UH, UISIL que no tienen pruebas de grado, y por otro lado; la UNICA y la Federada con solamente prueba de grado; la USL aporta otra opción la cual es realizar una práctica supervisada. Por otra parte, el peso relativo analizando el creditaje de los cursos, es exactamente igual que el porcentaje al hacer la distribución de los cursos, como puede determinarse con los datos de las tablas 14 y 15.

Tabla 15

Clasificación de los créditos en cada uno de los planes de estudio de universidades privadas estudiados en el nivel de licenciatura. Costa Rica, año 2017

\begin{tabular}{|c|c|c|c|c|c|c|c|c|c|c|c|c|c|c|}
\hline \multirow{3}{*}{ Temáticas } & \multicolumn{14}{|c|}{ Universidades } \\
\hline & \multicolumn{2}{|c|}{ Federada } & \multicolumn{2}{|c|}{ UH } & \multicolumn{2}{|c|}{ UNICA } & \multicolumn{2}{|c|}{ UCA } & \multicolumn{2}{|c|}{ UISIL } & \multicolumn{2}{|c|}{ UNADECA } & \multicolumn{2}{|c|}{ USL } \\
\hline & $\mathrm{Cr}$ & $\%$ & $\mathbf{C r}$ & $\%$ & $\mathrm{Cr}$ & $\%$ & $\mathrm{Cr}$ & $\%$ & $\mathrm{Cr}$ & $\%$ & $\mathrm{Cr}$ & $\%$ & $\mathrm{Cr}$ & $\%$ \\
\hline Educación & 20 & 41,7 & 24 & 50,0 & 16 & 50,0 & 20 & 62,5 & 24 & 80,0 & 24 & 80,0 & 16 & 57,1 \\
\hline Básicas & 8 & 16,7 & 4 & 8,3 & 4 & 12,5 & & & & & & & & \\
\hline Matemáticas & 4 & 8,3 & & & & & & & & & & & & \\
\hline Práctica & & & & & & & 4 & 12,5 & & & & & & \\
\hline Tecnología & & & 4 & 8,3 & & & & & & & & & 4 & 14,3 \\
\hline Investigación & 8 & 16,7 & 4 & 8,3 & 4 & 12,5 & 4 & 12,5 & 6 & 20,0 & 3 & 10,0 & 4 & 14,3 \\
\hline Otros & 8 & 16,7 & 12 & 25,0 & 8 & 25,0 & 4 & 12,5 & & & 3 & 10,0 & 4 & 14,3 \\
\hline Total & 48 & 100 & 48 & 100 & 32 & 100 & 32 & 100 & 30 & 100 & 30 & 100 & 28 & 100 \\
\hline
\end{tabular}

Fuente: Elaboración propia de la investigación con los datos expuestos en las mallas curriculares de las universidades privadas, en los sitios web respectivos o facilitados por CONESUP. 
Todas las universidades privadas estudiadas cuentan como requisito de graduación (algunas, bachillerato otras en licenciatura) el Trabajo Comunal Universitario (TCU), donde los estudiantes deben trabajar un número de horas establecido por la universidad en una comunidad, en un área relacionada a la que optan en su titulación.

\section{Cursos de matemática}

Para los descriptores de los cursos relacionados con matemáticas (Matemática General, Educación Matemática, Didáctica de la Matemática) se realizó la solicitud de los mismos a CONESUP en el año 2017; sin embargo, parte de la información que se otorgó estaba desactualizada, algunos planes con 20 años de antigüedad, o incompleta, por lo que se recurrió a revisar los sitios web oficiales de las universidades una vez comprobado que estaban impartiendo una carrera afín a este estudio durante el año citado; pero en la mayoría de los casos el descriptor de cada curso no se encuentra de manera pública en el sitio web, por lo que se optó por llamar o escribir un correo a las personas encargadas de las carreras de interés; en algunos casos no hubo respuesta por tanto se visitaron los respectivos campus universitarios, cabe resaltar que en una de las universidades se tuvo que pagar por el descriptor de cada curso. Lo anterior deja un sin sabor en esta investigación, ya que la información referida a una carrera, su malla curricular, descriptores de cursos, entre otros, que ofrecen las universidades deben ser componentes transparentes y de libre acceso para cualquier usuario.

Otra de las limitaciones enfrentadas es que los descriptores obtenidos contienen poca información, se limitan al nombre, código, créditos, objetivos y temas generales a impartir, por lo que en algunos casos se contactaron a los profesores que impartían los cursos para que se nos facilitarán los programas que se entregan a los estudiantes; sin embargo, solo se pudieron obtener los programas de los cursos impartidos por la UISIL y el del curso EB-032 de la UCA.

Debido a las situaciones descritas no fue posible obtener la información completa de cada universidad estudiada, sino algunos extractos. En la tabla adjunta se describen: la información relacionada con las horas contacto, las totales y el creditaje de cada curso. Las horas contacto son las que el estudiante debe asistir a clases, mientras que las horas totales suma las de contacto y las de trabajo independiente por parte del estudiante. 
ISSN Electrónico: 2215-3470

\section{Tabla 16}

Cursos ofrecidos por las universidades privadas relacionados al área de las matemáticas. Costa Rica, año 2017

\begin{tabular}{|c|c|c|c|}
\hline Universidad & Cursos ofrecidos (código y nombre) & $\begin{array}{l}\text { Horas contacto (horas } \\
\text { totales) }\end{array}$ & Créditos \\
\hline \multirow{12}{*}{ USJ (M) } & EDM-002 Matemáticas Básica y & $3(12)$ & 5 \\
\hline & Laboratorio Pedagógico & & \\
\hline & EDM-003 Matemática Básica II & $3(12)$ & 4 \\
\hline & EDM-004 Matemática Básica III & $3(12)$ & 4 \\
\hline & EDM-005 Matemática Básica IV & $3(12)$ & 3 \\
\hline & EDM-021 Geometría Elemental I & $3(12)$ & 4 \\
\hline & EDM-022 Geometría Elemental II & $3(12)$ & 4 \\
\hline & EDM-013 Estadística y Probabilidad & $3(12)$ & 4 \\
\hline & $\begin{array}{l}\text { EDM-025 Laboratorio Pedagógico I } \\
\text { para la Enseñanza de la Matemática }\end{array}$ & $3(12)$ & 5 \\
\hline & EDM-026 Laboratorio Pedagógico II & $3(12)$ & 5 \\
\hline & $\begin{array}{l}\text { para la Enseñanza de la Matemática } \\
\text { EDM-027 Evaluación aplicada a la Enseñanza } \\
\text { de la Matemática }\end{array}$ & & 4 \\
\hline & Total & 27 & 42 \\
\hline \multirow{5}{*}{ UNADECA } & Elementos de Estadística y Probabilidad & & 3 \\
\hline & Matemática para Escuela Primaria I & & 3 \\
\hline & Matemática para Escuela Primaria II & & 3 \\
\hline & Las Matemáticas y sus Procesos & & 3 \\
\hline & Total & & 12 \\
\hline \multirow{4}{*}{ UNICA } & E-004 Estadística & $3(12)$ & 4 \\
\hline & E-106 Matemáticas I & $3(12)$ & 4 \\
\hline & E-109 Matemáticas II & $3(12)$ & 4 \\
\hline & Total & $9(36)$ & 12 \\
\hline \multirow{3}{*}{ UCA } & EB - 025 Matemática I & $3(12)$ & 4 \\
\hline & EB - 032 Matemática II* & $5(12)$ & 4 \\
\hline & Total & $8(24)$ & 8 \\
\hline \multirow{3}{*}{$\mathrm{UH}$} & EP-15 Matemática I & $3(12)$ & 4 \\
\hline & EP-19 Matemática II & $3(12)$ & 4 \\
\hline & Total & $6(24)$ & 8 \\
\hline \multirow{3}{*}{ USL } & BED15 Matemática para I Ciclo & $3(12)$ & 4 \\
\hline & BED19 Matemática para II Ciclo & $3(12)$ & 4 \\
\hline & Total & $6(24)$ & 8 \\
\hline \multirow{3}{*}{ Federada } & PT-18 Matemáticas & $6(12)$ & 4 \\
\hline & PT-23 Didáctica de las Matemáticas & $6(12)$ & 4 \\
\hline & Total & $12(24)$ & 8 \\
\hline \multirow{3}{*}{ UISIL } & BAS-04 Enseñanza de la Matemática I* & 4 & 3 \\
\hline & BAS-12 Enseñanza de la Matemática II* & 4 & 3 \\
\hline & Total & 8 & 6 \\
\hline \multirow{2}{*}{ USJ (E) } & EDM-002 Matemáticas Básica y Laboratorio Pedagógico & $3(12)$ & 5 \\
\hline & Total & & 5 \\
\hline
\end{tabular}

Observaciones para la tabla:

La información descrita fue tomada del descriptor dado por CONESUP: UCA (existen diferencia entre la información de CONESUP y lo que dice el descriptor en cuanto a horas contacto), UH, UNICA, USL, Federada (habla de horas teóricas y prácticas que se consideró en esta investigación como presenciales).

Para la UISIL aunque se cuenta con los programas de los cursos impartidos en 2016 y el descriptor facilitado por la universidad y por CONESUP la información de la distribución de horas no es parte de dichos documentos.

Para el caso de la UNADECA no fue posible conseguir los programas ni los descriptores.

En la USJ existen diferencia entre el documento entregado por CONESUP y el descargable en el sitio web de la universidad en cuanto a créditos de los cursos, se consideró la información del sitio web por ser la más actualizada. En el caso de la distribución de horas se consideró la información de CONESUP, pero la malla tiene algunas diferencias.

Los cursos marcados con $(*)$ son los que se cuenta con el programa respectivo.

Fuente: Elaboración propia de la investigación con los datos expuestos en las mallas curriculares de las universidades privadas, en los sitios web respectivos, facilitados por CONESUP o por los docentes de las universidades. 
La universidad que destina menor cantidad de créditos al área de matemáticas es la USJ, en el caso de los énfasis en ciencias, inglés, estudios sociales y español con solamente un curso de 5 créditos, con tres horas de contacto en un cuatrimestre. Al considerarse que un docente de primaria para impartir matemáticas debe conocer y dominar conceptos básicos de esta asignatura, más aspectos didácticos y pedagógicos, esa cantidad de horas es muy limitada y en definitiva no se podrían abarcar todos los elementos esenciales que requiere un docente para impartir esas clases. Mientras que el énfasis en matemática dedica 42 créditos a cursos relacionados con matemática y educación matemática, con más de 27 horas contacto y más de 80 horas de estudio independiente, lo cual pareciera indicar que los estudiantes trabajan los tópicos básicos de esta asignatura; sin embargo, no se cuenta con el descriptor de ninguno de los cursos de esta universidad. La idea de tener una carrera en docencia de primaria con énfasis en matemáticas es considerada por formadores universitarios (PE1, PE3, PE4); sin embargo, para que tenga el resultado idóneo debe darse en las condiciones adecuadas; ya que actualmente, aunque tenga un énfasis particular, se contratará al docente para impartir las cuatro asignaturas, sin ninguna distinción, por parte del MEP.

Considerando el resto de las universidades que no tienen énfasis se observa que la de menor cantidad de créditos para matemáticas es la UISIL con dos cursos de tres créditos cada uno, donde las horas contacto, entre los dos cursos, es de ocho, este número de horas supera a la UH y a la USL, que aunque el creditaje es mayor, las horas contacto son tres por curso.

Todos los cursos, sin importar la cantidad de créditos, ni las horas contacto con el docente, se reportan con 12 horas totales; es decir entre las horas de clase (teoría y práctica) y las de estudio independiente que debe dedicar el docente en formación a tareas y estudio. También, es importante rescatar que la mayoría de los cursos, sin importar el número de créditos tienen tres horas contacto en el cuatrimestre; es decir cursos con un valor de tres créditos tienen tres horas contacto; mientras que cursos de cinco créditos también cuentan con tres horas de clase semanales al cuatrimestre, lo que revela una inconsistencia entre el valor que se le da a un curso, según el número de créditos y las horas tanto de estudio independiente como de contacto con un docente.

Existe mucha variedad en las mallas curriculares de las universidades privadas y en los cursos relacionados con matemáticas, como se citó anteriormente algunos coordinadores de carrera y profesores de cursos de matemáticas de diversas universidades fueron entrevistados, para tener un panorama más amplio de las acciones que se están llevando a cabo actualmente, uno de los aspectos tratados estuvo relacionado con los propósitos de esos cursos, a continuación se evidencian algunas de las opiniones.

Como se citó anteriormente, algunos de los programas de formación han pasado por un proceso de revisión y reformulación: E6 expresa "los programas que se utilizan en la actualidad fueron diseñados basándose en el currículo educativo de los planes de estudio del MEP y se usa como referencia programas de estudio de otras universidades. Fueron diseñados por expertos en cada área". PE6, docente de esta universidad, expresa que los programas de los cursos de matemáticas se han actualizado debido al cambio en el enfoque curricular del MEP. PE5 docente de la UISIL y coordinador de la carrera (P4), también cita que 
los programas de los cursos de matemáticas han sido revisados y reformulados en esta casa de enseñanza.

A lo largo de este documento se ha hecho referencia a la diversidad de los programas de formación relacionados con I y II ciclos en diversos aspectos, no escapa a este hecho los cursos de matemáticas, no solamente en creditaje, cantidad y horas contacto, sino que el enfoque que se les da.

Los egresados de estas carreras por lo general, van a ir a sus aulas de educación primaria a impartir clases en al menos las materias básicas, por lo que el conocimiento disciplinar que deben tener de cada área debe ser sólido, en las universidades privadas referenciadas en este estudio, sin incluir a la USJ que divide sus énfasis, como mínimo se dedica un curso a las matemáticas y en su mayoría trabajan con dos cursos para desarrollar conceptos básicos y didácticos de esta asignatura, por lo que le consultamos a los docentes de cursos de matemáticas si ellos consideraban que la formación que la carrera les ofrecía en esta área era suficiente para que el profesional egresado se desarrolle y cumpla las expectativas de la educación primaria, a lo cual E6 considera que en la UCA sí se da una formación adecuada para que sus egresados afronten la vida profesional de manera satisfactoria; sin embargo, agrega que los docentes deben actualizarse constantemente.

La decana de la Facultad de Educación de la UH expresa que se hacen esfuerzos, pero al no contar con especialistas en el área de matemáticas y su didáctica impartiendo los cursos, considera que aún se puede mejorar (E7); mientras que el coordinador de la carrera y profesor de cursos de matemática de la UISIL expresa que la cantidad de cursos (dos en este caso) es muy poco para que un estudiante que viene saliendo de secundaria puede abarcar los conocimientos básicos de la asignatura, más las nociones pedagógicas de la enseñanza, ya que no es lo mismo abarcar didáctica general que didáctica de las matemáticas; además que ingresan a la universidad con bases muy débiles en cuanto a conceptos básicos de esta asignatura (PE5).

Coincidimos con algunos de los entrevistados al plantear que en dos cursos es difícil que se puedan abarcar conocimientos básicos de las matemáticas y, además, los aspectos didácticos que son requeridos por los docentes; es decir en la mayor parte de los casos los graduados se están enfrentando a las aulas sin el conocimiento profesional adecuado. Aunado a si las bases con las que ingresan los estudiantes a las universidades no son sólidas en conceptos básicos y claro se agrava el problema de dedicar parte del tiempo que se tiene para didáctica, en recordar cómo realizar operaciones aritméticas básicas, sin el uso de una calculadora.

A continuación, se hace una descripción de algunos de los cursos de matemáticas impartidos por las universidades estudiadas; entre los aspectos considerados están el propósito del curso, la metodología implementada y la evaluación de este.

En la UISIL en el primer curso BAS04 , se trata de ofrecer una visión general de la estructura lógica de la matemática y del estudio didáctico y metodológico de los contenidos de esta asignatura propios de la educación general básica (UISIL, curso BAS-04, 2016) y en el segundo curso BAS12 , se trata de ofrecer escenarios escolares para desarrollar habilidad en el empleo de diferentes métodos y técnicas de enseñanza de la matemática en los diferentes ciclos de educación primaria (UISIL, curso BAS-12, 2016). En cuanto al desarrollo de los cursos impartidos, los estudiantes hacen 
asignaciones grupales, de investigación, exposiciones donde dan a conocer cómo se abordaría un determinado tema en el aula de primaria, por ejemplo, utilizando la tecnología. Para efectos de evaluación se tienen pruebas escritas, investigación, trabajo en clase, exposiciones (PE5).

En cuanto al curso EB - 032 Matemática II, impartido en la UCA, los objetivos están dirigidos a la aplicación de diferentes técnicas didácticas que fomenten el pensamiento crítico y el placer por el estudio de la matemática, al considerar los contenidos de I y II ciclo de la EGB; específicamente en las áreas: números, medidas, relaciones y álgebra, y geometría (PE6). Los objetivos generales son fundamentar los contenidos programáticos de I y II ciclo de la educación general básica en matemática y aplicar diferentes técnicas didácticas que fomenten el pensamiento crítico y el placer por el estudio de la matemática (UCA, curso EB032, 2017). La metodología que se trabaja en las clases es de tipo taller, con énfasis en la resolución de problemas. Para efectos de evaluación se utilizan guías de trabajo de los talleres realizados, pruebas y portafolio (PE6). Además, PE6 expresa que cada vez que se imparte este curso se hace un diagnóstico inicial de los conocimientos que traen los estudiantes para iniciar el abordaje de las áreas en función de las necesidades propias de cada grupo y se tiene mucha diversidad de un semestre a otro en cuanto a los resultados de este diagnóstico.

En cuanto al curso EP-15 Matemática I impartido en la UH, se pretende que los futuros docentes, comprendan la importancia de enseñar matemáticas y puedan utilizar la resolución de problemas para desarrollar los contenidos temáticos desde una participación activa y creativa, desde un espacio contextualizado en sus aulas. Este curso se enfoca en los contenidos de I ciclo de los Programas de Estudio del MEP de todas las áreas. En cuanto a la metodología utilizada en las clases se basa en la creatividad, a través del planteamiento de talleres enfocados a cada una de las áreas temáticas, con la intención de crear materiales didácticos que se pueden utilizar en el aula, se trabaja de manera grupal e individual, se utiliza la resolución de problemas, se desarrollan investigaciones y clases modelo. Para la evaluación sumativa de este curso se utilizan: análisis de lecturas, exposición de clase modelo, trabajo de investigación comunitaria y aplicación, diarios reflexivos y una prueba. (PE8).

Según PE8 en los cursos de matemáticas se realiza un repaso de sus fundamentos, con la intención de reforzar la temática en el docente en formación y, a la vez, dar diferentes técnicas para poder enseñar a los niños, los objetivos propuestos en los programas del MEP.

El curso EP-19 Matemática II, impartido en la UH, pretende formar educadores con dominio del uso de un conjunto de técnicas de diferentes filosofías y métodos que favorezcan el aprendizaje significativo, mediante material concreto y gráfico para que puedan trabajar en el aula los cinco procesos mentales establecidos en el currículo del MEP, y que se asocian a capacidades para la comprensión y uso de los conocimientos, este curso se orienta en los contenidos temáticos del II ciclo de la EGB en todas las áreas temáticas. En las clases se desarrollan diversas actividades, entre ellas: trabajo colaborativo, cooperativo, individual, grupal, resolución de problemas, investigación y práctica docente centrada en el área de matemáticas (los estudiantes deben efectuar observaciones de aula y analizar al respecto), para evaluar los aprendizajes se utilizan las siguientes técnicas: ensayo, pruebas parciales, presentación 
de materiales didácticos, trabajo de investigación, participación en una clase modelo y portafolio didáctico (PE8).

En síntesis, cada una de las universidades trata de abarcar los contenidos presentes en el currículo oficial del MEP, algunas trabajan primero los correspondientes al I ciclo y luego los del segundo (esto es común en las universidades privadas, no solamente se notó en las que se entrevistó al docente, sino que en los descriptores de los cursos facilitados por el CONESUP), otras prefieren trabajar por áreas sin importar el nivel educativo. Es decir, tratan de que el docente en formación adquiera conocimientos relacionados con el contenido específico; sin embargo, cabe rescatar que la lista de contenidos específicos no es incluida en los descriptores de los cursos solo se menciona que se abarcarán los contenidos del plan de estudios de I y II ciclos del MEP

En lo referente a la metodología en los cursos de matemáticas en el nivel universitario, es evidente que se trata de incentivar la criticidad y la creatividad de los docentes en formación, se trabaja de manera individual y grupal, se hace uso de la resolución de problemas, lo cual es un aspecto muy positivo porque los Programas de Estudio de Matemáticas del MEP propone que en las clases de primaria se debe trabajar la resolución de problemas.

En cuanto a la evaluación, hay similitud en que se realizan pruebas parciales, investigaciones, exposiciones, entre otras. $\mathrm{La}$ diversidad en las técnicas de evaluación es importante en un programa de formación, ya que busca mirar las habilidades de sus estudiantes desde diversas ópticas al considerar la diversidad de pensamiento y aprendizaje.

Cabe aclarar que la metodología empleada y las técnicas de evaluación aplicadas pueden cambiar de un semestre a otro, o de un docente a otro, las expuestas en este documento son las referenciadas por los entrevistados, no es que los descriptores de cada curso las definan.

En cuanto a las referencias bibliográficas al no tener la mayor parte de los programas de estudio no se pudieron revisar, y si se consideraban los documentos facilitados por CONESUP; las fuentes bibliográficas estaban muy desactualizadas.

\section{Comparación entre universidades públicas y privadas}

Sin importar si es una universidad privada o pública, al no existir lineamientos en cuanto a los nombres de las carreras, ni enfoque o cursos que deben tener las carreras relacionadas con I y II ciclo de la EGB, la oferta es muy diversa. La cantidad de créditos por curso varía entre dos y cinco, lo que equivale a una diferencia en cuanto al trabajo por parte del estudiante; sin embargo, las horas presenciales en la mayoría de las universidades privadas son tres sin hacer diferencias por cantidad de créditos.

De manera similar, no existen lineamientos sobre el perfil docente para impartir los distintos cursos, en algunas universidades consideran que cada asignatura debe ser impartida por un especialista en el área con cercanía al nivel de primaria (autor de libros, investigador en ese nivel, o contar con un título universitario que los respalde) y otras consideran que lo más importante es que el docente trabaje o haya trabajado en educación primaria, esta situación se da tanto en universidades privadas como públicas.

Solamente, las universidades estatales cuentan con la acreditación de sus carreras por parte del SINAES, lo cual puede significar un aspecto de análisis, ya que el número de graduados de las universidades privadas, tanto para bachillerato como para 
licenciatura, es mucho mayor que el de las estatales. SINAES es el único ente que actualmente acredita las carreras educativas en el país.

La mayoría de los coordinadores entrevistados, sin importar el tipo de universidad, consideran que en la formación referida al campo de las matemáticas y su enseñanza en los programas que ellos dirigen puede mejorar, sus razones son diversas, entre ellas: ausencia de especialistas en educación matemática para educación primaria, pocos cursos asignados, ingreso a la universidad con bases débiles en conceptos de matemáticas, entre otras.

Aunado a lo anterior algunos docentes formadores consideran que se puede mejorar la oferta que se da en el área de matemáticas, su principal preocupación radica en que el tiempo que tienen para desarrollar los programas de cada curso es limitado (PE1, PE2 y PE3). Por otro lado, PE4 considera que lo ideal sería que exista una carrera donde los docentes de primaria que van a impartir las clases de matemáticas se especialicen, ya que la formación que reciben en esta disciplina al ser generalísimos es muy poca; sin embargo, esto debe ser un proceso que se lleve de la mano con el MEP, porque actualmente, existe una universidad que trabaja por énfasis, pero para efectos de contratación no se considera, por el principal ente empleador.

Tanto docentes formadores de instituciones privadas como estatales consideran que los estudiantes que ingresan a las carreras de I y II ciclos traen bases deficientes de educación secundaria en matemáticas, por tanto en los cursos relacionados con esta asignatura deben dedicar tiempo a repasar o abordar conceptos que se suponía que los estudiantes ya manejaban, lo que implica una limitante, porque ya se cuenta con poco tiempo para desarrollar los contenidos propios del curso y si se deben repasar temáticas básicas conceptuales se hace más difícil la labor de formación (PE1, PE2, PE3 y PE5).

En cuanto a las mallas curriculares todas las universidades, sin importar su naturaleza, destinan el mayor porcentaje de cursos al área educación, todas tienen al menos uno relacionado con herramientas tecnológicas y ofrecen otros dedicados a la investigación en el nivel de licenciatura; algunas también dedican cursos en el nivel de bachillerato para este componente, esto es muy importante ya que un educador debe ser crítico y reflexivo en su práctica de aula.

Todas las universidades cuentan con al menos un curso destinado a práctica docente y la que más cantidad destina es la UNA.

En el caso de los cursos de matemática varían en cuando a cantidad, creditaje, horas contacto, características de quien los imparte; pero se pueden notar similitudes en la metodología que se emplea en las clases y las técnicas de evaluación; cabe destacar aquí que lo desarrollado en el aula universitaria, también dependen de la cantidad de horas contacto con el docente y de estudio independiente que se tienen por cada curso, donde dependiendo de la universidad van de 17 semanas, en el caso de algunas públicas a 14 semanas en el caso de algunas privadas. La cantidad de tiempo de clase que tiene un estudiante con el docente universitario le permite desarrollar actividades con supervisión, por lo que son muy importantes en la formación de estos.

En cuanto a la evaluación se utiliza variedad de técnicas e instrumentos lo cual es un aspecto positivo, porque estimula las diversas maneras en las que aprende un individuo; además se incentivan trabajos 
tanto individuales como grupales al generar así, el desarrollo de habilidades sociales y de trabajo cooperativo y colaborativo, esto se presenta en todas las universidades que se logró obtener la información respectiva.

\section{Conclusiones}

En esta investigación se pudo determinar que en Costa Rica no existe un programa estandarizado de formación de docentes para la educación primaria, lo que hace que la variedad en los programas ofrecidos por las universidades sea notoria, en aspectos como: nombre de la carrera, perfil de salida, tiempo de duración para obtener bachillerato, horas contacto de materias básicas (Estudios Sociales, Matemáticas, Ciencias y Español), entre otras; sin embargo, todas las titulaciones son consideradas de la misma manera, sin distinción, para la contratación, por parte del ente que emplea a la mayor cantidad de docentes que es el MEP.

Por lo anterior, consideramos que el gobierno nacional por medio del MEP debería establecer de manera clara los principios básicos para carreras relacionadas con I y II ciclos de la EGB, donde se indique como mínimo el perfil de salida requerido para ser contratado por este ente, duración de la carrera, el porcentaje mínimo de cursos y créditos que se debe abarcar por cada área de interés, ya sea de asignaturas básicas (Matemáticas, Ciencias, Estudios Sociales y Ciencias), así como de educación general, desarrollo del ser humano, neuroeducación, etc. Además, sería de vital importancia que se definan los estándares mínimos que deben tener los graduados de estas carreras en aspectos pedagógicos y de cada asignatura, en el caso particular de este artículo, relacionados con el área de las matemáticas.
En cuanto al perfil de las personas formadoras tampoco se establece nada oficial, lo que indica que la universidad decide si el docente del curso es especialista en la asignatura a desarrollar o en el campo profesional a desarrollarse; un ejemplo se observa en el área de las matemáticas, donde solamente tres de las universidades participantes consideran que los cursos de matemáticas deben ser impartidos por un docente con formación en esa asignatura; mientras que las otras tres consideran que el docente no requiere tener formación en matemáticas, sino tener experiencias en las aulas de primaria como educador.

Solamente, las universidades estatales cuentan con la acreditación por parte de SINAES, lo que indica que, de manera formal, únicamente, los planes de estudios de la UCR, UNA y UNED han sido evaluados por un ente externo a la institución para valorar la calidad académica de sus carreras.

Uno de los principios de transparencia radica en que la información debe encontrarse disponible al público en general y de manera especial para aquellos estudiantes interesados en cursar una de las carreras aquí citadas; sin embargo, las páginas web de la mayor parte de los centros educativos, no cuentan con el programa de la carrera, la malla curricular y los descriptores de cada curso, presente de manera abierta en un sitio web.

La responsabilidad que tiene un docente de primaria, actualmente, es muy grande, no solo debe dominar aspectos teóricos de diversas asignaturas, sino también, los didácticos, y del desarrollo físico y emocional de los individuos, es decir debe tener un conocimiento claro y amplio acerca del contenido que va a enseñar y a su vez un conocimiento pedagógico o didáctico. Según, la revisión documental que se hizo en esta investigación, las 
universidades están haciendo esfuerzos para desarrollar ambos dominios en los futuros docentes, de acuerdo con el modelo MKT, en algunas es más evidente que se hacen esfuerzos compartidos y en otras se nota un leve sesgo hacia la formación respecto al conocimiento pedagógico.

En el caso de esta investigación se consideró únicamente la responsabilidad en el área matemáticas, y se puede concluir que se debe trabajar mucho al respecto, ya que la cantidad de cursos es muy limitada, pero su aumento significaría un ampliación en la duración de las carreras, por lo que se deben buscar medidas efectivas, para que el desarrollo que se de en los pocos cursos con los que se cuentan, sea provechoso. Por otra parte, los estudiantes que ingresan a las universidades deberían contar con bases sólidas en conocimientos básicos de matemáticas, para que así, no se tenga que dedicar mucho tiempo al respecto, esta es una responsabilidad que debería ser asumida por varios actores en el país.

Por último, los programas de capacitación y actualización deben mejorarse, si no es posible abarcar muchos detalles en la formación universitaria inicial, deberían poder solventarse por medio de capacitaciones y actualizaciones impartidas por el MEP o por las universidades que forman los docentes.

\section{Reconocimientos}

Trabajo elaborado en el marco del proyecto de investigación Formación Docente en II Ciclo de la Educación General Básica, en cuanto al tema de las matemáticas de la Escuela de Matemática de la Universidad Nacional, bajo el código SIA 0082-16.

\section{Referencias bibliográficas}

Alfaro, A. L., Alpízar, M., Morales, Y., Ramírez, M. y Salas, O. (2013). La formación inicial y continua de docentes de matemáticas en Costa Rica. Cuadernos de investigación y formación en Educación Matemática, 8 (Especial), 131-179. Recuperado de https://revistas.ucr. ac.cr/index.php/cifem/article/view/12225

Ball, D., Thames, M. y Phelps, G. (2008). Content Knowledge for Teaching: What Makes It Special? Journal of Teacher Education, 59(5), 389-407. doi http://dx.doi. org/10.1177/0022487108324554

Camacho, M. y Rojas, K. (2013). La mirada de las profesoras coordinadoras de la intervención pedagógica en la carrera de Pedagogía con énfasis en I y II Ciclo. Revista Electrónica Educare, 17(3), 315-337. Recuperado de http://www.revistas.una.ac.cr/index.php/ EDUCARE/article/view/6598

Carrillo, J., Climent, N., Contreras, L. C. y Muñoz-Catalán, M. C. (2013). Determining specialised knowledge for mathematics teaching. En B. Ubuz, Ç. Haser, M. A. Mariotti, (Eds.), Proceedings of CERME 8 [Actas del Octavo Congreso de Investigación europea en Educación Matemática]. Congreso llevado a cabo en Turquía: Middle East Technical University and ERME. Recuperado de http://www.mathematik.uni-dortmund.de/ erme/doc/CERME8/CERME8_2013_Proceedings.pdf

Consejo Nacional de Rectores (2013). Lineamientos para la creación de nuevas carreras o la modificación de carreras ya existentes. Recuperado de http://www.documentos.una.ac.cr/ bitstream/handle/unadocs/6080/Lineamientos $\% 20$ aprob $\% 20 \% 20$ de $\% 20$ carreras $\% 20$ $\% 20 \% 28$ Fluxograma $\% 29 \% 20$ aprobado $\% 20$ el\%2022\%20de\%20octubre\%20de\%202013. pdf? sequence $=1 \&$ isAllowed $=\mathrm{y}$

Font, V. y Godino, J. D. (2011). Inicio a la investigación en la enseñanza de las matemáticas en secundaria y bachillerato. En Goñi, J. M. (Coord), Matemáticas: investigación, innovación y buenas prácticas. Editorial Graó. Barcelona, España.

Godino, J. D., Batanero, C., Font, V. y Giacomone, B. (2016). Articulando conocimientos y competencias del profesor de matemáticas: el modelo CCDM. En C. Fernández, J. L. 
González, F. J. Ruiz, T. Fernández y A. Berciano (Eds.), Investigación en educación matemática, XX (pp. 288-297). Málaga: SEIEM. Recuperado de http://www.seiem.es/docs/actas/20/ActasXXSEIEM.pdf

Llinares, S. (2008). Construir el conocimiento necesario para enseñar matemática. Prácticas sociales y tecnología evaluación e investigación, 1(3), 7-30.

Llinares, S. (2009). Competencias docentes del maestro en la docencia en matemáticas y el diseño de programas de formación. Uno: Revista de didáctica de las matemáticas, 51, 92-101. Recuperado de: https://rua.ua.es/dspace/bitstream/10045/13468/1/UNO_51-llinares.pdf

Martínez, M., Castillo, P., Trelles, C., Gonzales, N., Calle, E., Ayala, A,. Rivadeneira, F., Auccahuallpa, R., y Flores, M. (2017). Informe sobre la formación inicial y continua de profesores de matemáticas en el Ecuador. Cuadernos de investigación y formación en Educación Matemática, 12(16), 13-47. Disponible en http://funes.uniandes.edu.co/9451/1/Informe2017Martinez.pdf

Muñoz, C. (2008). Desarrollar competencias. Un desafío de los docentes de primaria. Aula de Innovación Educativa, 170, 13-15. Disponible en https://www.researchgate.net/publication/39222635_Desarrollar_competencias un_desafio_de_los_docentes_de_primaria

Pérez, A. (2010). Aprender a educar. Nuevos desafíos para la formación de docentes. Revista Interuniversitaria de Formación del Profesorado, 24 (2), 37-60. Disponible en http://www. redalyc.org/articulo.oa?id=27419198003

Pincheira, N. y Vásquez, C. (2018). Conocimiento didáctico-matemático para la enseñanza de la Matemática Elemental en futuros profesores de educación básica: diseño, construcción y validación de un instrumento de evaluación. Estudios Pedagógicos 44, 1. 25-48. Recuperado de http://revistas.uach.cl/index.php/ estped/article/view/3597

Rodríguez-Flores, A., Picado-Alfaro, M., Espinoza-González, J., Rojas-González, N., \& Flores-Martínez, P. (2016). Conocimiento común del contenido que manifiesta un profesor al enseñar los conceptos básicos de funciones: un estudio de caso. Uniciencia, 30(1), 1-16. https://doi.org/10.15359/ru.30-1.1.

Ruiz, A. (2014). La implementación de los programas oficiales de matemáticas. Ponencia presentada para el Quinto Informe del Estado de la Educación. Disponible en http:// www.estadonacion.or.cr/files/biblioteca_virtual/educacion/005/Angel_Ruiz_La_implementacion_programas_matemt.pdf

Ruiz, A., Barrantes, H., y Gamboa, R. (2009). Encrucijada en la enseñanza de la matemática: la formación de educadores. Cartago, Costa Rica: Editorial Tecnológica de Costa Rica.

Shulman, L. (1986). Those Who Understand: Knowledge growth in Teaching. Educational Researcher, 15(2), 4-14. doi : http://dx.doi. org/10.3102/0013189X015002004

Shulman, L. (1987). Knowledge and Teaching: foundations of the New Reform. Harvard Educational Review, 57(1), 1-22. doi http://dx.doi. org/10.17763/haer.57.1.j463w79r56455411

Sistema Nacional de Acreditación de la Educación Superior (2017). Sobre SINAES. Costa Rica: Sobre SINAES. Recuperado de http:/www. sinaes.ac.cr

Universidad de Cartago Florencio del Castillo (2017). Programa del curso EB032 Matemática II. Carrera Bachillerato en Ciencias de la Educación con énfasis en I y II Ciclo. Costa Rica.

Universidad de Costa Rica. (2014). Reestructuración Integral del Plan de Estudio de la Carrera de Bachillerato y Licenciatura en Educación Primaria. Escuela de Formación Docente. Costa Rica.

Universidad de Costa Rica. Escuela de Formación Docente. (2017). Programa de curso FD0401 Matemática en la Educación Primaria I. Carrera Bachillerato y Licenciatura en Educación Primaria, sede central. Costa Rica.

Universidad de Costa Rica. Escuela de Formación Docente. (2017). Programa de curso FD0515 Matemática en la Educación Primaria II. Carrera Bachillerato y Licenciatura en Educación Primaria, sede central. Costa Rica.

Universidad Estatal a Distancia. Escuela de Ciencias de la Educación (2017). Programa de curso 00809 Matemática I para I y II ciclos. Carrera Educación General I y II ciclos. Costa Rica.

Universidad Estatal a Distancia. Escuela de Ciencias de la Educación (2017). Programa de curso 00810 Matemática II para I y II Ciclos. Carrera Educación General I y II ciclos. Costa Rica.

Universidad Estatal a Distancia. Escuela de Ciencias de la Educación (2017). Programa de curso 02102 Matemática III para I y II Ciclos. Carrera Educación General I y II ciclos. Costa Rica. 
Universidad Estatal a Distancia. Escuela de Ciencias de la Educación (2018). Educación General Básica I y II Ciclos. Costa Rica: Ingreso. Recuperado de https://www.uned.ac.cr/ece/todas-las-categorias/44-carreras/i-ii-ciclos?start $=6$

Universidad Internacional San Isidro Labrador (2016). Programa del curso BAS 04 Enseñanza de la Matemática I. Carrera Bachillerato y Licenciatura en Ciencias de la Educación I y II Ciclos. Costa Rica.

Universidad Internacional San Isidro Labrador (2016). Programa del curso BAS 12 Enseñanza de la Matemática II. Carrera Bachillerato y Licenciatura en Ciencias de la Educación I y II Ciclos. Costa Rica.

Universidad Nacional. División de Educación Básica. (2017). Pedagogía con énfasis en I y II Ciclo de la Educación General Básica. [Tríptico]. Costa Rica: Programa de Publicaciones de la Universidad Nacional. Costa Rica. Recuperado de http://www.cide-basica.una. ac.cr/index.php?option $=$ com_remository \&Itemid $=77 \&$ func $=$ startdown $\&$ id $=105$

Universidad Nacional. División de Educación Básica. (2017). Programa de curso DBJ209 Didáctica de la Matemática para la Educación Básica. Carrera Bachillerato y Licenciatura en Pedagogía con énfasis en I y II Ciclo de la Educación General Básica con salida lateral de diplomado. Costa Rica.

Universidad Nacional. División de Educación Básica. (2017). Programa de curso DBJ402 Didáctica de las Ciencias y las Matemáticas para la Educación Básica. Carrera Bachillerato y Licenciatura en Pedagogía con énfasis en I y II Ciclo de la Educación General Básica con salida lateral de diplomado. Costa Rica.

\section{(c) (i) $(9)$}

La formación universitaria de docentes de educación primaria: el caso de matemáticas (Marianela Alpízar-Vargas y Ana Lucía Alfaro-Arce) por Revista Uniciencia se encuentra bajo una Licencia CreativeCommons Atribución-NoComercial-SinDerivadas 3.0 Unported. 